\title{
Panax ginseng components and the pathogenesis of Alzheimer's disease (Review)
}

\author{
MAYYA PETROVNA RAZGONOVA ${ }^{1}$, VALERY VYACHESLAVOVICH VESELOV ${ }^{2}$, \\ ALEXANDER MIKHAILOVICH ZAKHARENKO ${ }^{1}$, KIRILL SERGEYEVICH GOLOKHVAST $^{1}$, \\ ALEXANDER EVGENYEVICH NOSYREV ${ }^{2}$, GIANCARLO CRAVOTTO ${ }^{3}$, \\ ARISTIDIS TSATSAKIS ${ }^{4}$ and DEMETRIOS A. SPANDIDOS ${ }^{5}$
}

\begin{abstract}
${ }^{1}$ SEC Nanotechnology, Far Eastern Federal University, Vladivostok 690950; ${ }^{2}$ Center of Bioanalytical Investigation and Molecular Design, I.M. Sechenov First Moscow State Medical University, Moscow 119048, Russia; ${ }^{3}$ Department of Drug Science and Technology, University of Turin, Turin 10125, Italy; ${ }^{4}$ Department of Forensic Sciences and Toxicology, Faculty of Medicine, University of Crete; ${ }^{5}$ Laboratory of Clinical Virology, Medical School, University of Crete, Heraklion 71003, Greece
\end{abstract}

Received December 19, 2018; Accepted February 15, 2019

DOI: $10.3892 / \mathrm{mmr} .2019 .9972$

\begin{abstract}
Ginseng is one of the main representatives of traditional Chinese medicine and presents a wide range of pharmacological actions. Ginsenosides are the main class of active compounds found in ginseng. They demonstrate unique biological activity and medicinal value, namely antitumour, anti-inflammatory and antioxidant properties, as well as anti-apoptotic properties. Increasing levels of stress in life are responsible for the increased incidence of nervous
\end{abstract}

Correspondence to: Professor Aristidis Tsatsakis, Department of Forensic Sciences and Toxicology, Faculty of Medicine, University of Crete, Voutes, 71003 Heraklion, Greece

E-mail: aris@med.uoc.gr; tsatsaka@uoc.gr

Professor Kirill Sergeyevich Golokhvast, SEC Nanotechnology, Far Eastern Federal University, 8 Sukhanova Street, Vladivostok 690950, Russia

E-mail: droopy@mail.ru

Abbreviations: ACh, acetylcholine; AChE, acetylcholinesterase; $\mathrm{AD}$, Alzheimer's disease; ADAM, androgen deficiency of the aging male; ADAS, Alzheimer's disease assessment scale; ADAS-cog, Alzheimer's disease assessment scale-cognitive subscale; ADASnon-cog, Alzheimer's disease assessment scale-non-cognitive subscale; $\mathrm{AKT}$, protein kinase $\mathrm{B}$; APP, amyloid $\beta$ precursor protein; $\mathrm{A} \beta \mathrm{O}$, amyloid $\beta$ oligomer; BACE1, beta-secretase 1; Bax, Bcl-2-associated X-protein; BChE, butyrylcholinesterase; Bcl-2-protein, B-cell lymphoma 2; BDNF, brain-derived neurotrophic factor; cAMP, cyclic adenosine monophosphate; CDK, cyclin-dependent kinase; CDR, clinical dementia rating; ChAT, choline acetyltransferase; COX-2, cyclooxygenase 2; CREB, cAMP response element binding protein; ER, estrogen receptor; ERK, extracellular signal-regulated kinase; FAB, frontal assessment battery; GSH, glutathione; GSK3, glycogen synthase kinase-3; GSSG, glutathione disulphide; HSP, heat shock protein; IDE, insulin-degrading enzyme; IGF-1, insulin-like growth factor 1; IL, interleukin; IRE-1, inositol-requiring enzyme-1; LDH, lactate dihydrogenase; LPAR, lysophosphatidic acid receptor; system diseases. Neurological diseases create a huge burden on the lives and health of individuals. In recent years, studies have indicated that ginsenosides play a pronounced positive role in the prevention and treatment of neurological diseases. Nevertheless, research is still at an early stage of development, and the complex mechanisms of action involved remain largely unknown. This review aimed to shed light into what is currently known about the mechanisms of action of ginsenosides in relation to Alzheimer's disease. Scientific material and theoretical bases for the treatment of nervous system diseases with purified Panax ginseng extracts are also discussed.

LPC, lysophosphatidylcholine; MAP2, microtubule-associated protein 2; MAPK, mitogen-activated protein kinase; MDA, malondialdehyde; MMSE, Mini-Mental Status Examination; MWM, Morris water maze; NEP, neprilysin; NF- $\kappa \mathrm{B}$, nuclear factor- $\kappa \mathrm{B}$; NFT, neurofibrillary tangle; NO, nitric oxide; NOS, nitric oxide synthase; NOS1, nitric oxide synthase 1 (neuronal); NOS2, nitric oxide synthase 2 (inducible); OKA, okadaic acid; p-AKT, phosphorylated protein kinase $\mathrm{B}$; $\mathrm{PI}(4,5) \mathrm{P} 2$, phosphatidylinositol 4,5-bisphosphate; PI3K, phosphoinositide-3-kinase; PI4KII $\alpha$, phosphatidylinositol 4-kinase $2 \alpha$; PI4P, phosphatidylinositol 4-phosphate; p-JNK, phosphorylated-c-Jun N-terminal protein kinase; PKA, protein kinase A; PP-2A, protein phosphatase 2A; PPAR, peroxisome proliferator activated receptor; PS1, presenilin-1; $\mathrm{p}-\tau$, phosphorylated Tau protein; ROS, reactive oxygen species; SAPP $\alpha$, soluble amyloid precursor protein $\alpha$; SILAC, stable isotope labeling by amino acids in cell culture; SOD, superoxide dismutase; TNF- $\alpha$, tumour necrosis factor $\alpha$; TRAF2, tumour necrosis factor receptor-associated factor 2 ; TrkB, tropomyosin-tyrosine kinase receptor; QXG, quercetin 3-O- $\beta$-D-xylopyranosyl- $\beta$-D-galactopyranosyl

Key words: ginseng, nervous system diseases, Alzheimer's disease, ginsenosides, $\beta$-amyloid level 


\section{Contents}

1. Introduction

2. The history of ginseng as a drug

3. The chemical composition of Panax Ginseng C.A. Meyer

4. Ginsenosides and the acetylcholine level

5. Ginsenosides and the $\beta$-amyloid level

6. Ginsenosides and calcium ion levels in neurons

7. Ginsenosides and neuroinflammatory processes

8. Ginsenosides and the PI3K/Akt signalling pathway

9. Ginsenosides and the formation of neurofibrillary tangles

10. Ginsenosides and other factors

11. Ginsenosides and individuals with Alzheimer's disease

12. Conclusion

\section{Introduction}

Alzheimer's disease (AD), which is the most common form of dementia, is a neurodegenerative disease that was first described by the German psychiatrist, Alois Alzheimer in 1907 (1). Despite great progress being made in the understanding of the pathogenesis of AD, no cure has yet been found. Three main neuropathological signs characterize AD: The loss of neurons, amyloid plaques and neurofibrillary tangles (NFTs) (2). Amyloid plaques are predominantly composed of peptides, known as $\beta$-amyloid $(A \beta)$, which are the main peptides to induce neuronal damage and apoptosis in patients with AD (3). NFTs are formed from the hyperphosphorylation of Tau protein (also known as $\tau$ protein) $(4,5)$.

\section{The history of ginseng as a drug}

The ancient and rich experience of folk medicine in the countries of the Far East has paved the way for many valuable scientific medicines, and ginseng occupies a special place in this important group. The first information about this medicinal plant can be traced back into the distant past and is surrounded by an aura of legend and tradition. For dozens of centuries, ginseng has been the subject of worship for the peoples of the Far East and has played a significant role in the culture, commerce and even foreign policy of China and other East Asian states.

The first to discover the healing properties of ginseng, according to legend, is Lao Tzu (6th century BC), the founder of a religious and philosophical school in China. Ginseng has been known of for at least 4,000 years. The first mentions of it are found in the most ancient writings on medicinal plants, 'Shen-nun' and 'Shen-Lun-ben-cao', which date back to the 20 th century BC. Numerous recommendations for the treatment of various diseases with ginseng are available in the new edition of the 'E-lin' medicine collection, compiled in China by Shi Bao-yuan in 2-1 BC. Ginseng is also described in several ancient Chinese sources from the 3rd century onwards $(6,7)$.

Carl von Linné was the first to provide a systematic description of the genus and named it Panax L. (Linné, 1742; https://books. google.ru/books?id=30Y-AAAAcAAJ\&dq=Genera+Plantarum \&printsec $=$ frontcover\&source=bl\&ots=kI_cpWWP3x\&sig=Dbally FFHckeYxWqW-TegJC9iHs\&hl=en\&ei=07odS9_iE5HKsQPzotSECg $\& \mathrm{sa}=X \&$ oi=book_result\&ct=result\&redir_esc=y\#v=onepage $\&$ $\mathrm{q} \& \mathrm{f}=\mathrm{false}$ ). This title [from the Greek words 'pan' (meaning all) and 'asos' (meaning medicine)] reflects the idea of the allhealing properties of ginseng. Russian scientists have become increasingly interested in ginseng since the 19th century. The work of Kamensky (he studied Far Eastern ginseng for the first time) was followed by that of the Russian botanist and explorer, Carl Anton von Meyer (1841-1842) which deepened the knowledge of the taxonomy of the genus Panax and established the boundaries of the species, which are still accepted to this day. He described 5 types of ginseng and assigned the name of Panax Ginseng C.A.Meyer to true ginseng, and this name still holds to the present day (8,9; and Refs therein).

Reliable information on ginseng was provided by the writings of Far Eastern Russian researchers [Arsenyev (10), Przhevalsky (11), Maak (12), Maksimovich (13) and Komarov (14)]. In 1868, Y.K. Trapp (https://ru.wikipedia. org/wiki/Трапп,_Юлий_Карлович) included ginseng in his pharmacognosy guide.

Relevant studies on the biology and culture of ginseng [Shishkin (15), Gutnikova (16,17), Vysotsky (18), Bayanova (19) and Kurentsova (20)], have been carried out in the Far East of the former USSR since 1930. Several pharmacological [Zakutinsky (21), Burkat and Saksonov (22) and Kiselev (23)] and clinical works [Shapiro (24), Kuzminskaya (25) and Buturlin (26)] have been published since then. The Far Eastern academician scientists, Elyakov (founder of the Institute of the Far Eastern Branch of the Russian Academy of Sciences) and Brekhman provided significant contributions to the development of the science of Far Eastern medicinal plants, including ginseng (7,27).

The main active ingredients in ginseng are triterpene glycosides. These are ginsenosides, although they were more commonly known as panaxosides in the past. This was due to the fact that the pioneers of the study of ginseng saponins were domestic organic chemists under the guidance of the Academician of the Far East Branch of the Russian Academy of Sciences, G.B. Elyakov, who was the first to isolate 6 ginseng glycosides. The properties of an aglycone (a part of a glycoside that lacks a carbohydrate radical), led this group of scientists to term the glycosides of the protopanaxatriol group panaxosides, A, B and C, and the glycosides of the protopanaxadiol group panaxosides, D, E and F. Over time, other members of these groups were isolated; however, as there was no space left between $\mathrm{C}$ and $\mathrm{D}$, the new opening compounds were termed ginsenosides and numbers that correspond to their mobility on chromatograms were assigned to them $(7,28,29)$.

\section{The chemical composition of Panax Ginseng C.A.Meyer}

Saponins, which belong to the tetracyclic triterpene group, are among the biologically active substances (BAS) that are found in ginseng. Ginseng saponins are said to belong to the triterpenoid group of steroid origin (29).

Triterpene glycosides (ginsenosides) are considered the main active ingredients of ginseng, which were previously often termed panaxosides. The pioneers of the study of ginseng saponins are a group of Russian scientists led by the Academician Far Eastern Branch of the Russian Academy of Sciences, G.B. Elyakov. They were the first to isolate 6 glycosides of Panax ginseng in the 1960s $(6,7)$. They termed the glycosides of the protopanaxatriol group, panaxosides A, 
$\mathrm{B}$, and $\mathrm{C}$, based on the properties of the aglycone, and the glycosides of the protopanaxadiol group, the panaxosides D, $\mathrm{E}$ and F. Over time, other members of these groups were identified; however, since there was no space between C and D, newly discovered compounds began to be termed ginsenosides and assigned numbers to them corresponding to their mobility shown on the chromatograms.

When clarifying the structure of an aglycone that ginseng glycosides, it was found to contain 3-6 monosaccharide residues (glucose, rhamnose, arabinose and xylose). Almost all glycosides have two carbohydrate chains bound to aglycone through typical glycosidic bonds.

The systematization of the literature data on the chemical composition of ginseng has led to data that are presented in Table I.

It is now established that the composition of the dry root is approximately as follows: Ginsenosides, 1-6\%; carbohydrates (polysaccharides, trisaccharides, disaccharides, monosaccharides,cellulose,pectins),60-70\%; nitrogen-containing compounds (amino acids, etc.), 12-16\%; fat soluble components, 2\%; vitamins, $0.05 \%$; mineral substances $4-5 \%$ and moisture, $9-11 \%$ (28).

\section{Ginsenosides and the acetylcholine level}

Acetylcholine (ACh) is the main neurotransmitter in the parasympathetic nervous system and is rapidly destroyed by specific enzymes, known as cholinesterase, in the body.In addition to acetylcholinesterase (AChE), butyrylcholinesterase (BChE) can also destroy Ach (30). AChE and BChE play a significant role in $\mathrm{AD}$. The inhibition of $\mathrm{AChE}$ and $\mathrm{BChE}$ provides additional benefits in the treatment of asthma. The cholinergic hypothesis, according to which the disease is caused by the reduced synthesis of ACh, was the first hypothesis to be proposed as the cause of AD. Indeed, the concentration of $\mathrm{ACh}$ in the brain during the first stages of AD is significantly below normal, and a decrease in the activity of cholinergic neurons is observed as a result (31). AChE inhibition-based therapy, which aims to increase the amount of Ach, is a method with which to alleviate $\mathrm{AD}$ in the initial and moderate stages (32). There are currently some doubts as to the cholinergic theory, as drugs that increase the level of ACh have a low efficiency. However, impelling methods of maintenance therapy have been created on this basis (33). Donepezil, galantamine and rivastigmine are three AChE inhibitors that form the basis of maintenance therapy for individuals with asthma. The continuous use of these drugs can lead to side-effects, such as headaches, constipation, dizziness, nausea, vomiting and a loss of appetite, which severely affect the quality of life of patients (34).

AD presents with both increased AChE activation and the inhibition of choline acetyltransferase (ChAT), which is the enzyme responsible for ACh biosynthesis (35).

Molecular docking and in vitro analyses have demonstrated that some of the ginsenosides that are obtained from ginseng root are $\mathrm{AChE}$ and $\mathrm{BChE}$ inhibitors. Ginsenosides Rb1, Rb2, Rc, Re, Rg1 and Rg3 have a significant inhibitory effect against $\mathrm{AChE}$ and BChE. The ginsenoside Re appears to provide the optimal AChE inhibitory activity from a series of ginsenosides (36).

Theorder of the inhibitory potential was as follows: $\operatorname{Re}>\operatorname{Rg} 3>$ Rg1 $>$ Rb1 $>$ Rb2 $>$ Rc for AChE, and Rg3 $>$ Rg1 $>$ Rb2 $>$ Rb1 $>$ Re $>$ Rc for BChE. Ginsenoside Rc exhibited a weak inhibitory activity against $\mathrm{AChE}$, while ginsenosides Rc and Re did so against BChE, compared with the positive controls (36).

Five new ginsenosides that are derivatives of ursolic acid have been isolated from Panax japonicus (37). All five were identified as AChE inhibitors in an evaluation of AChE activity in a PC12 cell model (rat adrenal pheochromocytoma) that was treated with $A \beta_{25-35}$. However, it was found that their inhibitory potential was lower than that of donepezilum.

An extract from Panax quinquefolius (Cereboost ${ }^{\mathrm{TM}}$ ) was shown to exhibit AChE inhibitory activity in a mouse model of AD (male ICR mouse that received $\mathrm{A} \beta_{1-42}$ intracerebroventricular) (38). Cereboost ${ }^{\mathrm{TM}}$ increased the level of $\mathrm{ACh}$ in the brain by inhibiting $\mathrm{AChE}$ and reduced the level of $A \beta_{1-42}$, while it improved the cognitive abilities of mice. In vitro, Cereboost ${ }^{\mathrm{TM}}$ increased ChAT expression and reduced the cytotoxicity of $A \beta_{1-42}$. Identical results have been observed in other studies on mouse models of AD (ICR mice injected with scopolamine) (38). Ginsenoside Rg1 has been proven to be a more potent AChE inhibitor than Rb1 (40). Furthermore, ginsenoside $\mathrm{Rg} 5$ has been observed to dose-dependently inhibit $\mathrm{AChE}$ and activate ChAT in another model of AD (Wistar rats, which were injected with intracerebroventricular streptozocin). It also increased the ability of rats to learn and memorize the Morris water maze (MWM) (41).

It was also previously shown that an extract from a 4-year-old Panax ginseng C.A. Meyer root inhibited the neurotoxicity of $\mathrm{A} \beta$. Choi et al examined the effect of dried white ginseng extract (WGE) on neuronal cell damage and memory impairment in mice injected with intrahippocampal $\mathrm{A} \beta \mathrm{O}(10 \mu \mathrm{M})$. Mice were treated with WGE (100 and $500 \mathrm{mg} / \mathrm{kg} /$ day, p.o.) for 12 days after surgery. WGE improved memory impairment by inhibiting hippocampal cell death induced by $\mathrm{A} \beta \mathrm{O}$. In addition, the $\mathrm{A} \beta \mathrm{O}$-injected mice treated with WGE exhibited a restoration of reduced synaptophysin and ChAT intensity, and lower levels of ionized calcium-binding adaptor molecule 1 in the hippocampus compared with those of the vehicle-treated controls. These results suggest that WGE reverses memory impairment in AD by attenuating neuronal damage and neuroinflammation in the hippocampus of mice injected with $\mathrm{A} \beta \mathrm{O}$ (42).

Some studies have shown that ginsenosides exert a neuroprotective effect by acting on neurotransmitters in AD. For example, ginsenosides can increase the levels of $\gamma$-aminobutyric acid, Ach and dopamine, and reduce the levels of glutamate and aspartic acid in the hippocampus and cerebral cortex. In addition, ginsenosides can increase the level of glycine and serotonin in the blood (43). Apparently, ginseng contains substances that can increase the level of Ach in the brain of people with AD. Ginseng extracts can thus be used as palliative treatment in the early stages of AD.

\section{Ginsenosides and the $\beta$-amyloid level}

$\mathrm{A} \beta$ is the common name for several peptides that consist of 36-43 amino acid residues. The main species are the following: One peptide with 40 amino acid residues $\left(A \beta_{1-40}\right)$ and another of 42 amino acid residues $\left(A \beta_{1-42}\right)(44)$. $A \beta$ is formed in the body from $A \beta$ precursor protein (APP), which is a transmembrane protein that is concentrated in neurons through sequential prote- 
Table I. List of most known active components (ginsenosides) of Panax Ginseng C.A. Meyer.

$\begin{array}{lll}\text { No. } & \text { Chemical compounds } & \text { Structure }\end{array}$

1 20S-protopanaxadiol

(3S,5R,8R,9R,10R,12R,13R,14R,17S)-17-[(2S)-

2-hydroxy-6-methylhept-5-en-2-yl]-4,4,8,10,14-

pentamethyl- 2,3,5,6,7,9,11, 12,13,15,16,

17-dodecahydro-1H-cyclopenta[a]phenanthrene-3,12-diol

$\mathrm{C}_{30} \mathrm{H}_{52} \mathrm{O}_{3}$

$\mathrm{Mw}=460,743 \mathrm{~g} / \mathrm{mol}$

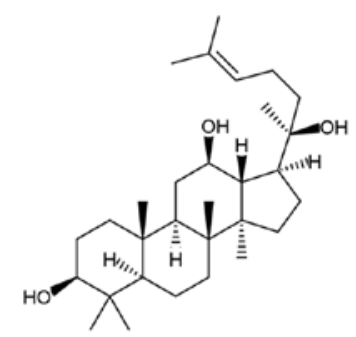

Panaxadiol

(3S,5R,8R,9R,10R,12R,13R,14R,17S)-4,4,8,10,

14-pentamethyl-17-[(2R)-2,6,6-trimethyloxan-2-yl]

-2,3,5,6,7,9,11,12,13,15,16,17-dodecahydro-1H-cyclo-

penta[a]phenanthrene-3,12-diol

$\mathrm{C}_{30} \mathrm{H}_{52} \mathrm{O}_{3}$

$\mathrm{Mw}=460,743 \mathrm{~g} / \mathrm{mol}$

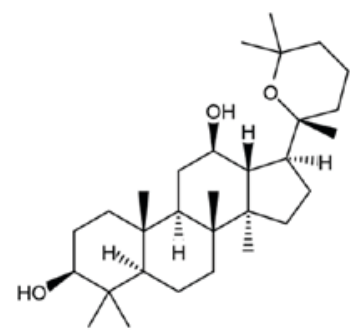

Ginsenoside a1 (Panaxoside a1) (pseudoginsenoside F11) 2-[2-[[(3S,6S,8R,10R,12R,13R,14R,17S)-3,12-dihydroxy-17[(2S,5R)-5-(2-hydroxypropan-2-yl)-2-methyloxolan-2-yl]-4, 4,8,10,14-pentamethyl-2,3,5,6,7,9, 11,12,13,15,16,17dodecahydro-1H-cyclopenta[a]phenanthren-6-yl]oxy]-4, 5-dihydroxy- 6-(hydroxymethyl)oxan-3-yl] oxy-6-methyloxane-3,4,5-triol

$\mathrm{C}_{42} \mathrm{H}_{72} \mathrm{O}_{14}$

$\mathrm{Mw}=801,024 \mathrm{~g} / \mathrm{mol}$

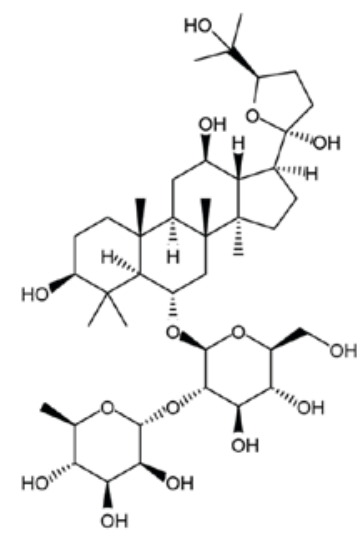
-3,12-dihydroxy-4,4,8,10,14-pentamethyl-17-[(2S)-6-methyl-2[(2S,3R,4S,5S,6R)-3,4,5-trihydroxy-6-(hydroxymethyl) oxan-2-yl]oxyhept-5-en-2-yl]-2,3,5,6,7,9,11,12,13,15,16, 17-dodecahydro-1H-cyclopenta[a]phenanthren-6-yl]oxy]-6(hydroxymethyl)oxane-3,4,5-triol

$\mathrm{C}_{42} \mathrm{H}_{72} \mathrm{O}_{14}$

$\mathrm{Mw}=801,024 \mathrm{~g} / \mathrm{mol}$

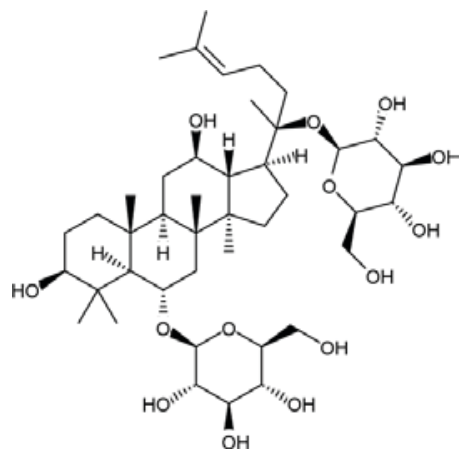

Ginsenoside Rb1 (Panaxoside Rb1)

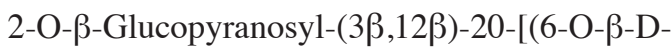
glucopyranosyl- $\beta$-D-glucopyranosyl)oxy]-12hydroxydammar-24-en-3-yl $\beta$-D-glucopyranoside $\mathrm{C}_{54} \mathrm{H}_{92} \mathrm{O}_{23}$ $\mathrm{Mw}=1109,307 \mathrm{~g} / \mathrm{mol}$

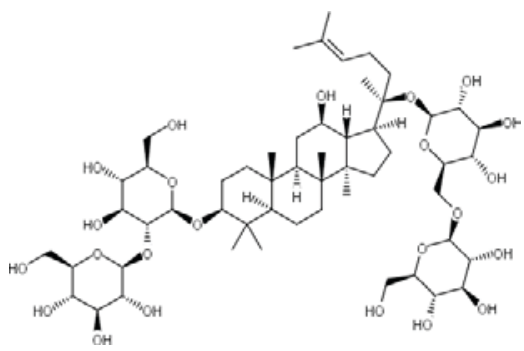


Table I. Continued.

No.

Chemical compounds

Structure

11 Ginsenoside Rg2 (Panaxoside Rg2)

$(3 \beta, 6 \alpha, 12 \beta)-3,12,20$-Trihydroxydammar-24-en-6-yl 2-O-

(6-deoxy- $\alpha$-L-mannopyranosyl)- $\beta$-D-glucopyranoside

$\mathrm{C}_{42} \mathrm{H}_{72} \mathrm{O}_{13}$

$\mathrm{Mw}=785,025 \mathrm{~g} / \mathrm{mol}$

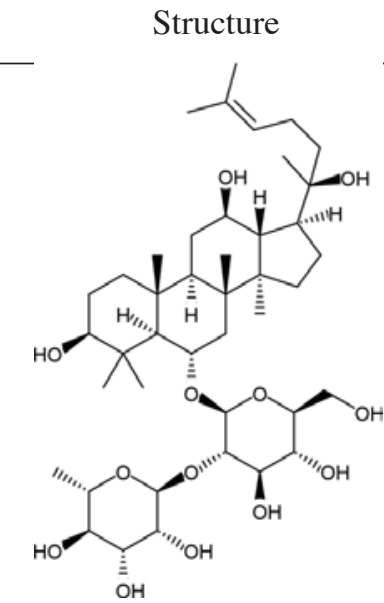

(2S,3R,4R,5R,6S)-2-[(2R,3R,4S,5S,6R)-2-[[(3S,5R,6S, 8R,9R, 10R,

12R, 13R,14R,17S)-3, 12-dihydroxy-4,4,8,10, 14-pentamethyl-17-

[(2Z)-6-methylhepta-2,5-dien-2-yl]-2, 3,5,6,7, 9,11,12,13,15,16,

17-dodecahydro-1H-cyclopenta [a]phenanthren-6-yl]oxy]-4,

5-dihydroxy-6-(hydroxymethyl) oxan-3-yl] oxy-6-methyloxane-3, 4,5-triol

$\mathrm{C}_{42} \mathrm{H}_{70} \mathrm{O}_{12}$

$\mathrm{Mw}=767,01 \mathrm{~g} / \mathrm{mol}$

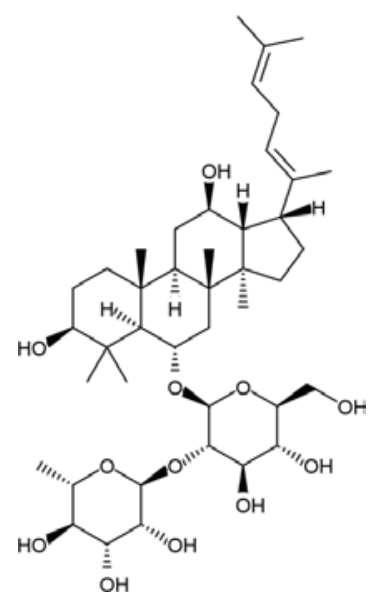

(2S,3R,4S,5S ,6R)-2-[(2S)-2-[(3S,5R,6S,8R,9R,10R,12R, 13R, 14R,17S) -6-[(2R,3R,4S,5S,6R)-4,5-dihydroxy-6-(hydroxymethyl)-3-[(2S,3R,4S, 5R)-3,4,5-trihydroxyoxan-2-yl] oxyoxan-2-yl]oxy-3, 12-dihydroxy-4,4, 8,10, 14-pentamethyl-2, 3,5,6,7,9,11,12,13,15,16, 17-dodecahydro-1H -cyclopenta[a]phenanthren-17-yl]-6-methylhept-5-en-

2-yl]oxy-6-(hydroxymethyl)oxane-3,4,5-triol

$\mathrm{C}_{47} \mathrm{H}_{80} \mathrm{O}_{18}$

$\mathrm{Mw}=933,139 \mathrm{~g} / \mathrm{mol}$

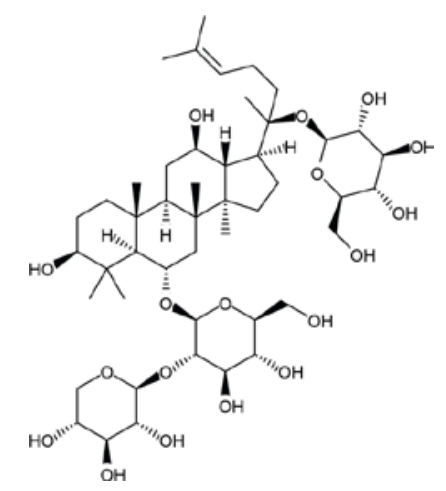

$3 \beta, 6 \alpha, 12 \beta)-20-(\beta-D-G l u c o p y r a n o s y l o x y)-3,12-$ dihydroxydammar-24en-6-yl 2-O-(6-deoxy- $\alpha$-L-mannopyranosyl)- $\beta$-D-glucopyranoside, Chikusetsusaponin IVc, Ginsenoside B2, NSC 308877, Panaxoside Re $\mathrm{C}_{48} \mathrm{H}_{82} \mathrm{O}_{18}$ $\mathrm{Mw}=947,166 \mathrm{~g} / \mathrm{mol}$

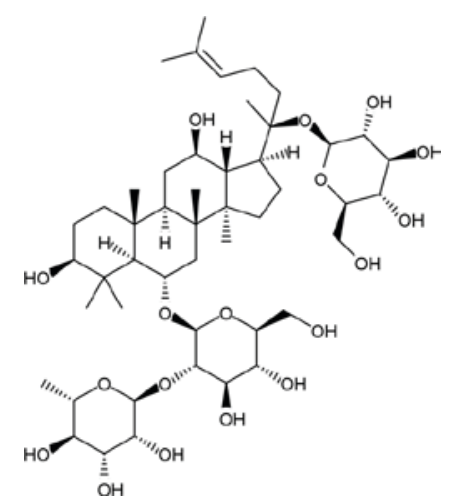


Table I. Continued.

No. Chemical compounds $\quad$ Structure

15 Ginsenoside Rh1 (Panaxoside Rh1)

(2R,3R,4S ,5S,6R)-2-[[(3S,5R,6S,8R,9R,10R,12R,13R,14R,17S)

-3,12-dihydroxy-17-[(2S)-2-hydroxy-6-methylhept-5-en-2-yl]-4,

4,8,10,14-pentamethyl-2,3,5,6,7,9,11,12,13,15,16,17-dodecahydro-1Hcyclopenta[a]phenanthren-6-yl]oxy]-6-(hydroxymethyl)oxane-3,4,5-triol $\mathrm{C}_{36} \mathrm{H}_{62} \mathrm{O}_{9}$ $\mathrm{Mw}=638,883 \mathrm{~g} / \mathrm{mol}$

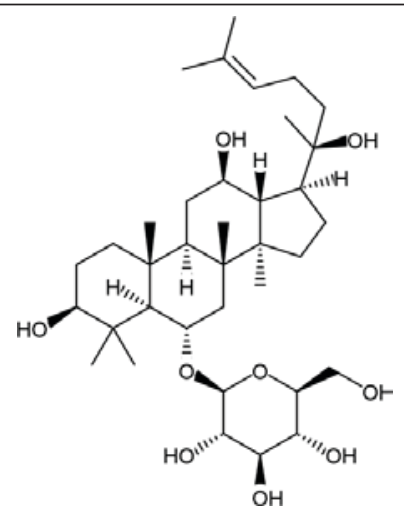

(2S,3R,4S ,5R)-2-[(2S,3R,4S,5S,6R)-2-[(2R,3R,4S,5S,6R)-4, 5-dihydroxy-2-[[(3S,5R,8R,9R,10R,12R,13R,14R,17S)-12-hydroxy-17[(2S)-2-hydroxy-6-methylhept-5-en-2-yl]-4,4,8,10,14-pentamethyl-2,3, $5,6,7,9,11,12,13,15,16,17$-dodecahydro- $1 \mathrm{H}$ cyclopenta[a]phenanthren-3-yl]oxy]-6-(hydroxymethyl)oxan-3-yl]oxy-4, 5-dihydroxy-6-(hydroxymethyl)oxan-3-yl] oxyoxane-3,4,5-triol

$\mathrm{C}_{47} \mathrm{H}_{80} \mathrm{O}_{17}$

$\mathrm{Mw}=917,14 \mathrm{~g} / \mathrm{mol}$

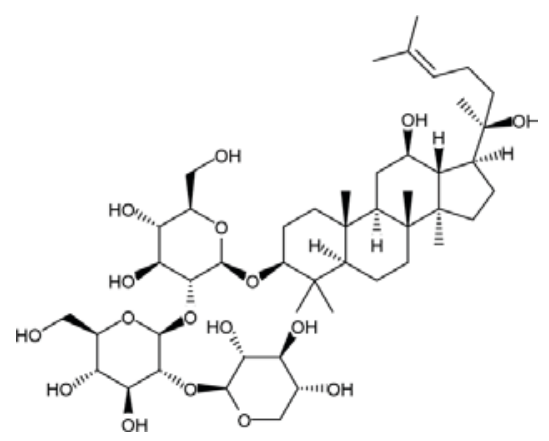

olysis with beta secretase 1 (BACE1) and $\gamma$-secretase (45). A $\beta$ forms insoluble $A \beta$ filaments, which subsequently stick together in the intercellular space into dense formations known as senile plaques (46). There is also an alternative, non-amyloidogenic pathway, in which the first cleavage of APP is catalysed, not by BACE1, but by $\alpha$-secretase and the result is soluble amyloid precursor protein $\alpha$ (sAPP $\alpha$ ), which exerts anti-apoptotic and neuroprotective effects $(47,48)$.

Some ginsenosides are BACE1 inhibitors as molecular docking and in vitro in studies have demonstrated. Their inhibitory ability decreases in a certain order: $\mathrm{Rc}>\operatorname{Rg} 1>\operatorname{Rb} 2>\operatorname{Rb} 1>\operatorname{Rg} 3>\operatorname{Re}(36)$. Ginsenoside Re has not only been observed to reduce the activity of BACE1 and the expression of BACE1, but also to not affect the total levels of APP and sAPP $\alpha$ in a N2a/APP695 cell model (neuronal cells with an overexpression of APP) (49). It has also been shown that the decrease in BACE1 expression is associated with the activation of ginsenoside Re by peroxisome proliferator-activated receptor $\gamma(\operatorname{PPAR} \gamma)$. Ginsenoside $\operatorname{Rg} 1$ is also a stimulator of PPAR $\gamma$ (50). The role of PPAR $\gamma$ in the pathogenesis of AD is not yet fully known.

Yan et al (51) demonstrated that ginsenoside Rd promoted the activation of the non-amyloidogenic pathway by activating estrogen receptor (ER). The methods they used in their study were as follows: $10 \mathrm{mg} / \mathrm{kg}$ ginsenoside $\mathrm{Rd}$ in ovariectomy/ ovariectomized $(\mathrm{OVX})+$ ginsenoside $\mathrm{Rd}$ group and an equivalent volume of saline in the sham-operated group and OVX group were administrated intraperitoneally for two months, respectively. The MWM was used to examine the cognitive function of rats, and the levels of sAPP $\alpha$ and A $\beta$ in the hippocampi were measured. The culture medium of HT22 hippocampal neuronal cells was incubated with ginsenoside Rd, ER antagonist (ICI182.780), MAPK inhibitor (PD98059), or PI3K inhibitor (LY294002), respectively. The sAPP $\alpha$ levels were measured, and the expression levels of $\alpha$-secretase, sAPP $\alpha, \beta$-secretase, A $\beta$, phosphorylated AKT (p-AKT), total AKT, p-ERK, total ERK, p-ER $\alpha$, total ER $\alpha, p-E R \beta$ and total $\operatorname{Er} \beta$ were examined by western blot analysis to investigate the estrogenic-like activity of ginsenoside Rd.

Accordingly, ginsenoside Rd was also found to attenuate cognitive and memory impairment, increase the levels of sAPP $\alpha$ and to reduce extracellular A $\beta$ in OVX rats. In HT22 cells, ginsenoside Rd upregulated the sAPP $\alpha$ levels, which were inhibited by the inhibitors of the MAPK and PI3K pathways. In addition, the inhibitor of ER prevented the ginsenoside Rd-induced release of SAPP $\alpha$ and the activation of the MAPK and PI3K pathways. Ginsenoside Rd increased the expression of $\alpha$-secretase and sAPP $\alpha$, while it decreased the expression of $\beta$-secretase and $\mathrm{A} \beta$. Moreover, ginsenoside $\mathrm{Rd}$ promoted the phosphorylation of ER $\alpha$ at the Ser118 residue (51). Similar results have also been obtained for ginsenoside $\operatorname{Rg} 1(52,53)$.

It has been demonstrated that ginsenosides $\mathrm{Rd}$ and $\mathrm{Rg} 1$ not only significantly reduce the level of $\mathrm{A} \beta$, but also increase the level of SAPP $\alpha$, as it has been shown in animal models of AD (54).

Huang et al (55) aimed to investigate the effects of Panax notoginseng saponins (PNS) on $\alpha$-secretase and 
$\beta$-secretase involved in A $\beta$ generation in SAMP8 mice. The results of their study revealed that PNS increased $\alpha$-secretase activity perhaps by enhancing the level of ADAM9 expression, which itself was achieved by the upregulation of the expression of the ADAM9 gene. PNS significantly decreased the BACE1 protein level by downregulating the level of $B A C E 1$ gene expression and consequently precluded the activity of $\beta$-secretase (56).

That study indicated that PNS modulated the expression levels of proteins and genes associated with $\alpha$ - and $\beta$-secretase, thereby increasing $\alpha$-secretase activity and reducing $\beta$-secretase activity, which may be one of the mechanisms of action of PNS precluding A $\beta$ generation. Accordingly, PNS may be a promising agent for AD (55).

Endres and Fahrenholz (57) noted in their research that a disintegrin and metallopeptidase domain 10 (ADAM10) presents a worthwhile target with respect to the treatment of a neurodegenerative diseases, such as AD. Animal models with an overexpression of ADAM10 revealed a beneficial profile of the metalloproteinase with respect to learning and memory, plaque load and synaptogenesis. Initially, ADAM10 was suggested to be an enzyme, shaping the extracellular matrix by cleavage of collagen type IV, or to be a tumour necrosis factor $\alpha(\mathrm{TNF}-\alpha)$ convertase. In a relatively short period of time, a wide variety of additional substrates [with amyloid precursor protein (APP) probably being the most prominent] have been identified and the search is still ongoing. Hence, any side-effects concerning the therapeutic enhancement of ADAM10 $\alpha$-secretase activity have to be considered (57).

However, in another stdy, the level of $\operatorname{APP} \alpha$ was found to be higher in mice that were treated with ginsenoside Rh2 than in the control group. Ginsenoside Rh2 inhibited the endocytosis of APP and increased the distribution of APP on the cell membrane, thereby reducing the amyloid and increasing the non-amyloid pathway of cleaving APP (58). It has been proven that the level of cholesterol in neurons is involved in the pathogenesis of AD (59), and that the C-terminus of APP contains a cholesterol-binding domain (60).

Since it is known that the lipid raft is a specific cell membrane that is enriched with cholesterol, which plays an important role in the endocytosis of transmembrane proteins (61), and treatment with ginsenoside Rh2 significantly reduces the level of cholesterol in neurons, it has been concluded that the distribution of APP over the cell membrane is determined by the cholesterol in neurons (58). In addition to cholesterol, other lipids, such as phosphoinositides, are also involved in the pathogenesis of AD (62). One of the key phospholipids, phosphatidylinositol 4,5-bisphosphate [PI(4,5)P2], is formed by phosphatidyl inositol 4-phosphate (PI4P) phosphorylation using a specific enzyme, phosphatidyl inositol-phosphate-4 kinase type $1 \gamma$. PI4P is formed via phosphatidylinositol by phosphatidylinositol-4-kinase $2 \alpha$ (PI4KII $\alpha$ ) (63). In vitro and in vivo, ginsenoside $\mathrm{Rg} 3$ has been observed to increase the levels of PI4P and $\mathrm{PI}(4,5) \mathrm{P}_{2}$ by activating PI4KII $\alpha(64) . \mathrm{PI}(4,5) \mathrm{P}_{2}$ contributes to the regulation of the mobility of transmembrane proteins in lipid rafts (65). In other words, $\mathrm{PI}(4, \mathrm{v} 5) \mathrm{P}_{2}$ leads to changes in the fluidity and thickness of the membrane, and this, in turn, affects the activity of $\gamma$-secretase (66). Thus, high levels of PI4P and $\mathrm{PI}(4,5) \mathrm{P}_{2}$, induced by ginsenoside $\mathrm{Rg} 3$, reduce the generation of $A \beta$ by altering the activity of $\gamma$-secretase. The cognitive abilities of the animals in the MWM test following treatment with ginsenosides increased in all experiments, in relation to the control group with the AD model without treatment with ginsenosides $(51-54,58)$.

Substances from ginseng extracts directly or indirectly affect the activity of secretases. However, such an approach to AD treatment appears to provide low-probability outcomes, as demonstrated by the fact that a number of large pharmaceutical companies have completed the clinical trials of various secretase inhibitors ahead of time: Verubecestat (67), lanabecestat (BACE1 inhibitors) (https://www.astrazeneca.com/mediacentre/press-releases/2018/update-on-phase-iii-clinical-trials-oflanabecestat-for-alzheimers-disease-12062018.html) and semagacestat ( $\gamma$-secretase inhibitor) (68). There was no improvement in patients who were taking the BACE1 inhibitors compared to the placebo group. The first and second phases of the clinical trials of semagacestat revealed a decrease in the plasma $A \beta_{1-42}$ concentration at $3 \mathrm{~h}$ after administration. However, the concentration increased by $300 \%$ after $15 \mathrm{~h}$, while there was no reduction in the cerebrospinal fluid. Although semagacestat reduced the number of amyloid plaques, the cognitive functions of the patients taking semagacestat worsened compared with the placebo group $(67,68$; https://www.astrazeneca.com/ media-centre/press-releases/2018/update-on-phase-iii-clinicaltrials-of-lanabecestat-for-alzheimers-disease-12062018.html).

It has been proven in vivo that ginsenoside $\mathrm{Rg} 3$ reduces the level of $\mathrm{A} \beta$ by increasing the activity and expression of neprilysin (69). Ginsenoside Rg1 has also been shown to increase the activity and expression of neprilysin (70). Neprilizin is one of the main enzymes that is capable of destroying $A \beta$.

It is known that protopanaxadiol (PPD)-type saponins are completely metabolized to $20-O-\beta$-D-glucopyranosyl-20(S)-p rotopanaxadiol (M1) by intestinal bacteria when taken orally; M1 and ginsenoside Rb1, as a representative of PPD-type saponins, were thus examined for cognitive disorders.

In a mouse model of $\mathrm{AD}$ induced by $\mathrm{A} \beta_{25-35}$ intracerebroventricular injection, impaired spatial memory was recovered by the p.o. administration of ginsenoside Rb1 or M1 (71). Although the expression levels of phosphorylated NF-H and synaptophysin were reduced in the cerebral cortex and the hippocampus of mice injected with $A \beta_{25-35}$, their levels in the ginsenoside Rb1- and M1-treated mice were almost completely recovered to those of the control levels. The potencies of the effects did not differ between ginsenoside Rb1 and M1 when administered orally, suggesting that most of the ginsenoside Rb1 may be metabolized to M1, and M1 is an active principal of PPD-type saponins for memory improvement. M1 was shown to be effective in vitro and in vivo, indicating that ginseng drugs containing PPD-type saponins may reactivate neuronal function in AD by p.o. administration.

It has been demonstrated that AD is closely related to APP and presenilin-1 (PS1), which are overexpressed in AD (72). A study of UPLC/MS based metabolomics was conducted in order to better understand the mechanisms of action of ginsenoside $\operatorname{Rg} 1$ and $\operatorname{Rg} 2$, which counteract AD. The results revealed that ginsenosides $\mathrm{Rg} 1$ and $\mathrm{Rg} 2$ reduced rescue latency, compared to the AD model group, when cognitive function was tested in the MWM (71).

The impaired cognitive function and increased hippocampal $\mathrm{A} \beta$ deposition in mice with $\mathrm{AD}$ were ameliorated by ginsenoside $\operatorname{Rg} 1$ and $\operatorname{Rg} 2$. In addition, a total of 11 potential 
biomarkers that are associated with the metabolism of lysophosphatidylcholines (LPCs), hypoxanthine and sphingolipids were identified in the brains of mice with AD and their levels were partly restored following treatment with ginsenoside Rg1 and $\mathrm{Rg} 2$. Ginsenoside $\mathrm{Rg} 1$ and $\mathrm{Rg} 2$ treatment influenced the levels of hypoxanthine, dihydrosphingosine, hexadecasphinganine, LPC C 16:0, and LPC C 18:0 in mice with AD. Additionally, G-Rg1 treatment also influenced the levels of phytosphingosine, LPC C 13:0, LPC C 15:0, LPC C 18:1 and LPC C 18:3 in mice with AD (73).

A total of ten potential biomarkers were identified that were associated with the metabolism of lecithin, amino acids and sphingolipids in mice with AD. The peak intensities of LPC, tryptophan and dihydrosphingosine were lower, while those of phenylalanine were higher, in the mice with AD than in the control mice. Ginsenoside Rg1 treatment affected all three metabolic pathways, while ginsenoside Rb1 treatment affected lecithin and amino acid, but not sphingolipid metabolism. These data suggest that metabolomics has acquired a new method with which to discover the therapeutic benefits of ginsenosides in the treatment of AD (74).

Transgenic mice with AD have been used to study the protective properties of ginsenoside $\mathrm{Rg} 1$ on brain activity and synaptic plasticity, using conditional reflex fading and the western blotting technique. The results revealed that long-term memory improves following treatment with ginsenoside $\mathrm{Rg} 1$. Furthermore, ginsenoside $\mathrm{Rg} 1$ did not have a negative effect on normal diet and weight, while also inhibiting the levels of C-terminal fragments (CTF), phosphorylated $\tau$-protein (p-Tau) and $A \beta_{1-42}$ in mice with AD. Ginsenoside Rg1 was also able to improve the expression of brain-derived neurotrophic factor (BDNF) and tyrosine receptor kinase B (TrkB) in the hippocampus. The results revealed that ginsenoside $\mathrm{Rg} 1$ exerted a neuroprotective effect via the activation of the BDNF-TrkB pathway and that weakened the expression of $\mathrm{AD}$-associated proteins (75).

Furthermore, ginsenoside Rg1 has been found to increase the expression of N-methyl-D-aspartate receptor 1 (NR1) and N-methyl-2B D-aspartate (NR2B), while also attenuating the formation of NFTs, which directly affect the processes of learning and memory in mouse models with AD (76). It was discovered in recent studies that reproductive sex hormones, particularly oestrogen, play an important role in the pathogenesis of AD. The rapid decline in oestrogen levels in postmenopausal women increases susceptibility to AD (77-79).

Thus, the absence of oestrogen can be a risk factor for AD. Zhang et al conducted a successful study to examine the neuroprotective effects of ginsenoside $\operatorname{Rg} 1$ on an OVX and D-galactose (D-gal)-injected rat model of AD (54). The results revealed that ginsenoside Rg1 not only restored impaired cognitive activity and positively affected spatial learning and memory, but also reduced the production of $A \beta_{1-42}$ in the rats with AD. Seven weeks after surgery, ADAM10 expression in the hippocampus of the rats with AD was markedly decreased, while BACE1 expression increased compared with that in the sham-operated group $(\mathrm{P}<0.05)$. The levels of cleaved caspase- 3 were increased in the hippocampus of rats with AD. Ginsenoside Rg1 and E2 treatment increased the ADAM10 level, while it reduced the BACE1 level and apoptosis.
Moreover, moderate-dose i.e., $10 \mathrm{mg} / \mathrm{kg} /$ day and high-dose i.e., $20 \mathrm{mg} / \mathrm{kg} /$ day ginsenoside $\mathrm{Rg} 1$ exerted more poten effects than low-dose i.e., $5 \mathrm{mg} / \mathrm{kg} /$ day ginsenoside Rg1 (54). It is well known that chronic stress restrictions (in animals) can accelerate the process of AD generation and development. Ginsenoside Rg1 protects from oxidative damage by reactive oxygen species (ROS) and inhibits the expression of NADPH oxidase 2 (NOX2), p47phox and RAC1 (80).

The association between ginsenoside Rg1 and the endoplasmic apoptotic pathway, as mediated by the reticulum, has also been examined in a rat model of AD. The results revealed that ginsenoside Rg1 reduced the accumulation of NFTs and the number of terminal deoxynucleotide transferase-mediated dUTP filamentous ends that mark positive cells in mice with AD. More importantly, ginsenoside Rg1 inhibited the activation of apoptosis-associated phosphorylated-c-Jun N-terminal protein kinase (p-JNK) and reduced the expression of glucose-regulated protein 78 (Grp78). Consequently, ginsenoside $\mathrm{Rg} 1$ exerted a neuroprotective effect by inhibiting the accumulation of NFTs and A $\beta$ via inhibition of the ER stress-mediated pathway. The blocking of this pathway was triggered by the inositol-requiring enzyme-1 (IRE-1) and tumour necrosis factor receptorassociated factor 2 (TRAF2) pathway, as a result of the inhibition of the expression of p-JNK (81).

A scientific study found that pseudoginsenoside $\mathrm{F}_{11}\left(\mathrm{PF}_{11}\right)$, one of the components of ginseng, exerted a neuroprotective effect and enhanced the activity of neurons (82). Another study demonstrated that $\mathrm{PF}_{11}$ reduced the latency of rescue in the MWM and blocked the reduction of stepwise latency in the step test for $\mathrm{A} \beta_{11-42}$ and APP/PS1 mice. In addition, $\mathrm{PF}_{11}$ inhibited APP expression and the production of $A \beta_{11-42}$ in the hippocampus and cortex of APP/PS1 mice. $\mathrm{PF}_{11}$ significantly increased the activity of superoxide dismutase (SOD) and glutathione peroxidase and reduced the amount of malondialdehyde (MDA). In addition, $\mathrm{PF}_{11}$ reduced the expression of JNK2, p53 and cleaved caspase-3. Thus, the improved recognition that is observed when subjects are exposed to ginsenoside $\mathrm{PF}_{11}$ may be associated with anti-inflammatory, anti-apoptotic and inhibitory effects on amyloid genesis (83). By analogy, it has been found that ginsenoside R1 exerts a protective effect against A $\beta$-neurotoxicity (84).

In a previous study, ginsenoside $\mathrm{Rb} 1$ also reduced the presence of $A \beta_{1-42}$ in the area of the cortex and hippocampus as well as improving the ability to learn in mice with AD (85). It is well known that cyclooxygenase 2 (COX-2), IkB- $\alpha$ and neuronal nitric oxide (NO) synthase (nNOS) are markers of neuroinflammation. Ginsenoside Rb1 reduced the number of COX-2-positive cells and positive IkB- $\alpha$ cells and increased the number of nNOS-positive cells in the hippocampus, as compared to the model group. The neuroprotective effect of ginsenoside Rb1 may thus be associated with anti-inflammatory markers in the hippocampus of mice with AD (85). More importantly, ginsenoside Rb1 has been observed to be more rapidly absorbed than ginsenoside $\mathrm{Re}$ and $\mathrm{Rg} 1$ (86). The effect of ginsenoside Rb1 may therefore be more potent than that of the other ginsenosides. In addition, ginsenoside Rb1 also demonstrated higher activity against neurotransmitters. For example, ginsenoside Rb1 has a higher absorbing activity against ONOO(-) than ginsenoside Rb2, Rc, Re, Rg1 and Rg3 (36). 
Studies have shown that ginsenoside Rd can improve learning ability and memory, and can reduce neuronal death and loss in the CA1 region of the hippocampi of mice with AD. Moreover, ginsenoside Rd decreased the expression of ionized calcium-binding adaptor molecule 1 (Ibal), glial fibrillar acid protein (GFAP), interleukin (IL)-1 $\beta$, IL-6, TNF- $\alpha$, caspase-3 and $\mathrm{S} 100 \beta$ mRNA. Ginsenoside Rd has also been observed to increase IL-10 and HSP70 mRNA expression levels (87). Furthermore, ginsenoside $\mathrm{Rd}$ has been shown to inhibit the expression of $\mathrm{NF}-\kappa \mathrm{B}$ p 65 , which is an important marker of the NF- $\mathrm{B}$ pathway (88). These findings indicate that the anti-inflammatory, antioxidant and anti-apoptotic effects of ginsenoside $\mathrm{Rd}$ are responsible for its neuroprotective effects.

$\mathrm{AChE}$ and BChE play a significant role in AD. The inhibition of $\mathrm{AChE}$ and $\mathrm{BChE}$ provides additional benefits to the treatment of AD. Ginsenosides Rb1, Rb2, Rc, Re, Rg1 and $\operatorname{Rg} 3$ have been shown to exert significant inhibitory effects against AChE and BChE. The Re compound of the series of ginsenosides inhibits the activity of AChE with optimal results (36). It has been demonstrated that ginsenosides exert neuroprotective effects via acting on neurotransmitters in AD. For example, ginsenosides can increase the levels of $\gamma$-aminobutyric acid, Ach and dopamine and reduce the levels of glutamate and aspartic acid in the hippocampus and cerebral cortex. Moreover, ginsenosides can increase the level of glycine and serotonin in the blood (43). These studies provide a novel method for AD treatment.

Apart from ginsenosides, the glycolipoprotein fractions of ginseng extracts (gintonin) have also been the subject of an AD model study, which made five observations to indicate that gintonin counteracts the development of $\mathrm{AD}$ : Gintonin has been shown to promote the production of sAPP $\alpha$ by activating ADAM10, inhibit A $\beta$ production in a dose-dependent manner, activate PI3K and AKT, and also not only to alleviate memory impairment caused by $\mathrm{A} \beta$ neurotoxicity, but also reduces the deposition of amyloid plaques in a mouse model of AD (89).

\section{Ginsenosides and calcium ion levels in neurons}

The mechanism of the neuronal damage that is caused by an increase in the intracellular level of calcium ions $\left(\mathrm{Ca}^{2+}\right)$, which is in turn induced by glutamate, has been well studied (90). An increase in $\mathrm{Ca}^{2+}$ levels leads to the excessive stimulation of proteolytic enzymes, an increase in lipid peroxidation and an increase in the generation of ROS and nitrogen $(91,92)$, thereby contributing to the excitotoxic process. $A \beta$ not only causes the addition of new ion channels in the cell membrane, but also promotes the phosphorylation of existing calcium channels, thereby increasing the flow of calcium and initiating neurodegeneration (93). A $\beta$ increases the phosphorylation of membrane-bound proteins and decreases the phosphorylation of cytosolic proteins, via MAPK, with the result that the intracellular level of $\mathrm{Ca}^{2+}$ increases (94). Ginsenoside $\operatorname{Rg} 2$ can significantly reduce the intracellular level of $\mathrm{Ca}^{2+}$ and ROS that is caused by $\mathrm{A} \beta_{25-35}$ in the PC12 cell model (95). In another study, ginsenoside $\mathrm{Rg} 2$ has been found to reduce not only the level of $\mathrm{Ca}^{2+}$, but also the lipid peroxidation that is caused by glutamate (96).

Notably, while ginsenoside Rb1 can reduce the intracellular level of $\mathrm{Ca}^{2+}$ when it was increased by administering $\mathrm{A} \beta_{25-35}$, the intracellular level of $\mathrm{Ca}^{2+}$ in healthy cells is not affected (97).
Ginsenoside Rg1 has been observed to suppress the sensitivity of calcium channel activation to high values of membrane potential in an animal model of AD [Sprague Dawley (SD) rats administered $\left.\mathrm{A} \beta_{25-35}\right]$. This effect disappears when ginsenoside Rg1 is used together with the MAPK inhibitor, PD98059 (98).

Quan et al (98) demonstrated that $\mathrm{Rg} 1$ treatment significantly reduced peak ICa, HVA densities, inhibited the sensitivity of channel activation to voltage, and enhanceed the sensitivity of channel inactivation to voltage; these effects of Rg1 were effectively inhibited by the MAPK inhibitor, PD98059. This indicated that Rg1 reduced A $\beta$-induced HVA calcium channel currents via MAPK in hippocampal neurons. The resulting reduced calcium influx may downregulate the level of calcium ions in the neurons and attenuate the neurotoxicity of $A \beta$. In summary, the data of that study demonstrated that Rg1 can reduce HVA calcium channel currents via MAPK in hippocampal neurons in A $\beta$-exposed brain slices (98).

As mentioned above, the intracellular concentration of $\mathrm{Ca}^{2+}$ is an important indicator of neurological disorders. Increased $\mathrm{Ca}^{2+}$ levels may increase the manifestation of epilepsy. Ginsenosides, in general and ginsenoside $\mathrm{Rg} 3$, in particular, can inhibit an increase in $\mathrm{Ca}^{2+}$ that is induced by $\mathrm{Mg}^{2+}$. Ginsenosides can modulate the disrupted $\mathrm{Ca}^{2+}$ homeostasis by inhibiting the glutamate ionotropic receptors that selectively bind N-methyl-D-aspartate (NMDA receptors) (99). In addition, oxidative stress can lead to hippocampal degeneration. It is noteworthy that ginsenosides reduce the oxidative stress that acts upon the parts of the nerve ending that correspond to the synapse (synaptosomes), and reduce the synaptic vesicles of dose-dependent presynaptic terminations. Moreover, it is not adenosine A1 receptors or adenosine A2B receptors, but adenosine $\mathrm{A} 2 \mathrm{~A}$ receptors that play an important role in the fight against epilepsy. Thus, ginsenosides exert an antiepileptic effect that they exert by activating the Adenosine-A2A receptors (100) (Table II).

An increase in the intracellular levels of $\mathrm{Ca}^{2+}$ mediates the activation of calcium-dependent enzymes, such as calpain (calcium-dependent non-lysosomal cysteine proteases). Calpain II is involved in the regulation of the apoptosis of certain cell types and performs this role by interacting with cysteine protease caspase-3, which has been identified as a key factor in apoptosis (101). The expression of calpain II and caspase-3 in vivo has been found to be reduced under the influence of ginsenoside $\operatorname{Rg} 2$ (96). The decrease in the activity of caspase-3 is caused by an increase in the B-cell lymphoma protein 2 (Bcl-2)/Bcl-2-associated X-protein (Bax) ratio, which is caused by ginsenoside $\operatorname{Rg} 2$ (95).

Caspase-3 is involved not only in the regulation of cell apoptosis, but also in the proteolytic cleavage of APP, with the formation of $A \beta$. The caspase-3-mediated proteolysis site is located in the cytoplasmic tail of APP, and cleavage at this site occurs in vivo in the hippocampal neurons following acute excitotoxic or cerebral ischemia reperfusion injury (102). An increased caspase-3 activity and expression have been observed in rat models of $\mathrm{AD}$; however, the activity and expression of caspase-3 decreases markedly following treatment with ginsenosides $\operatorname{Rg} 1$ and $\operatorname{Rd}(81,87)$. The protein fraction, extracted from 4-year-old ginseng root, is also able to reduce the expression of caspase-3, as well as increase the Bcl-2/Bax ratio (103). 
Table II. Pharmacological activity and mechanism of ginsenoside action on epilepsy, depression and reperfusion injury of the brain.

\begin{tabular}{|c|c|c|}
\hline $\begin{array}{l}\text { Pharmacological } \\
\text { intervention }\end{array}$ & Ginsenosides & Impact mechanism \\
\hline \multirow[t]{2}{*}{ Anti-epileptic effect } & All ginsenosides & Activation of adenosine-A2A receptors \\
\hline & $\operatorname{Rg} 3$ & $\begin{array}{l}\text { Modulation of } \mathrm{Ca}^{2+} \text { disrupted homeostasis via } \\
\text { the inhibition of the nanomethylenediamine receptor }\end{array}$ \\
\hline \multirow[t]{6}{*}{$\begin{array}{l}\text { Anti-depressant } \\
\text { effect }\end{array}$} & $\operatorname{Rg} 1$ & $\begin{array}{l}\text { Increased levels of phosphorylation of protein kinase A } \\
\text { and levels of phosphorylation of the cAMP-response } \\
\text { elements of the activating protein. Expression of the } \\
\text { hippocampal transmission pathway of the neurotrophic } \\
\text { factor of the brain, hippocampal neurogenesis }\end{array}$ \\
\hline & All ginsenosides & Increased plasma ACTH levels and CORT blood levels \\
\hline & $\mathrm{Rb} 1$ & Activation 5-HT2A receptor \\
\hline & $\mathrm{Rb} 3$ & $\begin{array}{l}\text { Stops the process of reducing the mass of the hippocampus } \\
\text { of the brain and the level of BDNF in the hippocampus }\end{array}$ \\
\hline & $\mathrm{CK}$ & $\begin{array}{l}\text { Activation 5-HT2A receptor for the manifestation of } \\
\text { the antidepressant effect, the regulation of levels of } \\
\text { NA, ACTH and CORT in the brain. }\end{array}$ \\
\hline & $\operatorname{Rg} 3$ & $\begin{array}{l}\text { Facilitation of the hippocampal-signalling pathway of } \\
\text { BDNF, regulation of thelevels of NA, } \\
\text { ACTH and CORT in the brain area. }\end{array}$ \\
\hline \multirow[t]{6}{*}{$\begin{array}{l}\text { Protection against } \\
\text { cerebral ischemia } \\
\text { reperfusion injury }\end{array}$} & $\operatorname{Rg} 1$ & $\begin{array}{l}\text { Decreases levels IL- } 1 \beta, \text { TNF- } \alpha \text { and HMGB1, suppresses the } \\
\text { expression of cleaved caspase- } 3 \text { and cleaved caspase- } 9 \text {. } \\
\text { Downregulation of proteinase-activated receptor- } 1 \text { (PAR-1) } \\
\text { mRNA levels activated by protease }\end{array}$ \\
\hline & $\mathrm{Rb} 1$ & $\begin{array}{l}\text { Cancels the signalling pathway activation of NF- } \kappa \mathrm{B} \text { and the } \\
\text { increase in TNF- } \alpha \text { and IL- } 6 \text { levels in the ischemic hemisphere. } \\
\text { It prevents the reduction of thioredoxin- } 1 \text { and } \\
\text { superoxide dismutase and improves the expression of }\end{array}$ \\
\hline & & $\begin{array}{l}\text { HSP } 70, \text { Akt and the p-NF- } \mathrm{BB} \text { p } 65 \text { block when occluding } \\
\text { the middle cerebral artery. }\end{array}$ \\
\hline & $\mathrm{Rd}$ & $\begin{array}{l}\text { Improves neuronal viability by inhibiting the overactive } \\
\text { phosphorylation of NMDAR } 2 \mathrm{~B} \text { and reducing levels } \\
\text { of expression in the cell membrane }\end{array}$ \\
\hline & $\operatorname{Re}$ & $\begin{array}{l}\text { Neuroprotective action by significantly reducing } \\
\text { MDA and increasing the activity of } \mathrm{H}^{+} \text {-ATPhase }\end{array}$ \\
\hline & $\operatorname{Rg} 3$ & $\begin{array}{l}\text { Reduces the expression of calpain I and caspase- } 3 \\
\text { mRNA in the CA } 1 \text { region of the hippocampus }\end{array}$ \\
\hline
\end{tabular}

Authors/(Refs.)

Shin et al (100)

Doody et al (68)

Jiang et al (160), Liu et al (161)

Wang et al (151), Kang et al (153)

Yamada et al (152)

Cui et al (162)

Zhang et al (154), Yamada et al (152)

Zhang et al (154), You et al (155)

Bao et al (126), Zhou et al (127)

Yang et al (129),

Xie et al (131),

Sun et al (132),

Huang et al (150)

Huang et al (150)

Zeng et al (149)

Liu et al (156),

Xie et al (157)

Chen et al (158)

He et al (159)

BDNF, brain-derived neurotrophic factor; NA, noradrenaline; ACTH, adrenocorticotropic hormone; CORT, corticosterone; HMGB1, high mobility protein group; PAR-1, protein and receptor-1 mRNA; NF, nuclear factor; HSP70, heat shock protein 70; NMDAR 2B, N-methyl-d-aspartate receptor 2B; MDA, malondialdehyde; TNF- $\alpha$, tumour necrosis factor $\alpha$.

Other components of ginseng, apart from ginsenosides, are capable of influencing the intracellular level of $\mathrm{Ca}^{2+}$. Quercetin 3-O- $\beta$-D-xylopyranosyl- $\beta$-D-galactopyran osyl (QXG) has been isolated from Panax notoginseng root.
Of note, a previous study demonstrated that following the introduction of $\mathrm{A} \beta$ into cortical neurons and PC12 cells alone, the intracellular level of $\mathrm{Ca}^{2+} \mathrm{w}$ not altered. However, following pre-treatment with QXG, the level of $\mathrm{Ca}^{2+}$ which 
was increased by $\mathrm{A} \beta$ was decreased by $50 \%$. QXG also reduced the $A \beta$ levels and caspase- 3 activity in vivo (104).

\section{Ginsenosides and neuroinflammatory processes}

$\mathrm{NF}-\mathrm{kB}$ is a transcription factor with various functions that is closely associated with the inflammatory response, the immune response and other pathological and physiological processes. $\mathrm{NF}-\mathrm{\kappa B}$ is in the cytoplasm in an inactive form in a normal state. When NF- $\mathrm{kB}$ is activated and enters the nucleus, it binds to target genes and induces transcription (105). NF- $\mathrm{kB}$ activates the transcription of TNF- $\alpha$, various ILs (IL-1 $\beta$ and IL-6) and other target genes during inflammation, and contributes to the production of cytokines. It has also been found that NF- $\kappa B$ is associated with neurodegenerative diseases and is activated in the cerebral cortices of patients with $\mathrm{AD}$ (106). It has been shown, for ginsenoside Rb1 (107) and Rg5 (41) in vitro and for ginsenoside $\mathrm{Rd}(88)$ in vivo, that these ginsenosides are capable of reducing the expression of anti-inflammatory factors (IL-1 $\beta$, IL- 6 and TNF- $\alpha$ ) and increasing the expression of IL-10 (for $\mathrm{Rb} 1$ and Rd) by suppressing the activation of NF- $\mathrm{\kappa B}$.

COX-2 is a key enzyme in the synthesis of prostaglandins and is an important mediator of inflammation (108). NO is a short-lived neurotransmitter that plays an important role in learning and memory mechanisms. As a result, impaired NO synthesis can lead to memory impairment and a decrease in learning ability (109). The fact that a number of inflammatory molecules can regulate the expression of NO synthases [NO synthase 1 (neuronal) (NOS1) and NO synthase 1 (inducible) (NOS2)] suggests that NOS should be considered a neuroinflammatory marker (110). The levels of COX-2 and NOS2 have been observed to increase significantly in models of $\mathrm{AD}$ (Wistar rats, administration of either $\mathrm{A} \beta$ or streptozocin), while the level of NOS1 decreases compared to the control group. However, treatment with ginsenoside $\operatorname{Rg} 5$ lowers the levels of COX-2 and NOS2 compared to the control values (41), and the level of COX-2 also decreases following treatment with ginsenoside Rb1, and the level of NOS1 increases (85).

Li et al examined the effect of ginsenoside $\mathrm{Rg} 2$ on neurotoxic activities induced by glutamate in PC12 cells (96). The results revealed that glutamate decreased cell viability, increased intracellular $\mathrm{Ca}^{2+}$ lipid peroxidation (the excessive production of MDA and $\mathrm{NO}$ ) and the protein expression levels of calpain II, caspase- 3 and A $\beta_{1-40}$ in PC12 cells. Ginsenoside Rg2 significantly attenuated the glutamate-induced neurotoxic effects upon these parameters at all doses tested. Their study suggested that ginsenoside $\mathrm{Rg} 2$ exerted a neuroprotective effect against glutamate-induced neurotoxicity through mechanisms related to anti-oxidation and anti-apoptosis. In addition, the inhibitory effect of ginsenoside $\mathrm{Rg} 2$ against the formation of $A \beta_{1-40}$ suggested that ginsenoside $\mathrm{Rg} 2$ may also represent a potential treatment strategy for AD (96).

Li et al investigated and evaluated the neuroprotective effects of ginseng protein (GP) and its possible mechanisms of action in a cellular and animal model of AD. The results demonstrated that GP $(10-100 \mu \mathrm{g} / \mathrm{ml})$ significantly improved the survival rate of neurons and reduced cell apoptosis and the mRNA expression of caspase- 3 and Bax $/ \mathrm{Bcl}-2$. In addition, GP $(0.1 \mathrm{~g} / \mathrm{kg})$ significantly shortened the escape latency, prolonged the crossing times and the percentage of residence time; reduced the level of $\mathrm{A} \beta_{1-42}$ and $\mathrm{p}-\mathrm{Tau}$, the activity of t-NOS and iNOS, and the content of MDA and NO, improved the activity of SOD, the concentration of cyclic adenosine monophosphate (cAMP) and the protein expression of p-PKA/PKA and cAMP response element binding protein (p-CREB/CREB) (103).

Ginseng extracts also exhibit antioxidant properties in AD models. In fact, ginsenoside $\mathrm{Rg} 2$ has been shown to decrease the concentration of MDA (a marker of lipid peroxidation) (96) and the level of ROS in vivo (95). The GP fraction activates SOD (antioxidant enzyme) and reduces the concentration of MDA in vitro (103). Furthermore, QXG prevents the formation of $\mathrm{H}_{2} \mathrm{O}_{2}$-induced ROS generation in a dose-dependent manner in vitro (104).

\section{Ginsenosides and the PI3K/Akt signalling pathway}

As mentioned above, ginseng root components are able to affect the PI3K/Akt signalling pathway. The PI3K/Akt signalling pathway is one of the most important signalling pathways with which cells can avoid apoptosis and it plays a significant role in oxidative stress in AD. Kashour et al (110) examined the role of the late Simian virus 40 transcription factor (LSF), in anti-apoptotic APP pathways. The expression of wild-type human APP (hAPPwt) inhibited staurosporine (STS)-induced apoptosis and this inhibition was further enhanced by the expression of LSF. Thus, Kashour et al (111) established a connection between APP, LSF and AD. Akt (p-Akt) hyperphosphorylation regulates apoptotic factors, such as Bcl-2 and Bax, downstream signalling pathways, which allows for the regulation of apoptosis (112). The suppression of the PI3K/Akt signalling pathway promotes cell apoptosis, while the activation of the PI3K/Akt signalling pathway leads to the phosphorylation of the Akt cascade, which, in turn, protects the cells from oxidative stress (113).

Cui et al examined the protective effects of ginsenoside $\operatorname{Rg} 2$ on $A \beta_{25-35}$-induced neurotoxicity to PC12 cells and identified a potential molecular signalling pathway involved. Ginsenoside Rg2 attenuated the cleavage of caspase-3 induced by $\mathrm{A} \beta_{25-35}$ thereby improving cell survival and significantly enhanced the phosphorylation of Akt in PC12 cells. Additionally, pre-treatment with PI3K inhibitor, LY294002, completely abolished the protective effects of ginsenoside Rg2 against $\mathrm{A} \beta_{25-35}$-induced neuronal cell apoptosis. These findings unambiguously suggested that the protective effect of ginsenoside $\mathrm{Rg} 2$ against the $\mathrm{A} \beta_{25-35}$-induced apoptosis of PC12 cells was associated with activation of the PI3K/Akt signalling pathway (95).

Li et al examined the therapeutic effect of GP on $\mathrm{AD}$ and its association with the PI3K/Akt signalling pathway in order to elucidate the mechanisms underlying the neuroprotective effects of ginseng (114). It was found that the cognitive abilities of the rats with $A D$ were increased and the level of $A \beta$ was also reduced by treatment with GP. GP also reduced the content of $\mathrm{A} \beta_{1-42}$ and p-Tau, and increased the mRNA and protein expression of PI3K, p-Akt/Akt and Bcl-2/Bax in the hippocampus (114).

\section{Ginsenosides and the formation of neurofibrillary tangles}

As mentioned above, AD is characterized by the accumulation of NFTs in cerebral tissue. NFTs are mainly composed of 
hyper p-Tau. $\tau$-protein is a microtubule-related protein that is expressed in the central nervous system. It induces microtubule assembly and stabilisation. However, excessive p-Tau forms NFTs and leads to synaptic dysfunction, neuronal degeneration and cognitive impairment (115). In addition, abnormal hyperphosphorylation renders the $\tau$-protein resistant to proteolytic degradation, which leads to the gradual accumulation of $\mathrm{p}$-Tau in the cell and promotes the formation of NFTs. The inhibition of $\mathrm{p}$-Tau can therefore be a potential therapeutic strategy for the prevention of AD.

Okadaic acid (OKA), a potent phosphatase inhibitor, often used to mimic the symptom of AD damaged by NFTs, was used in the study by Song et al to examine the effects of ginsenoside Rg1 on memory improvement and related mechanisms in SD rats. According to their study, it can be concluded that ginsenoside Rg1 protects rats from OKA-induced neurotoxicity. The possible neuroprotective mechanisms may be that Rg1 decreases OKA-induced memory impairment through the glycogen synthase kinase 3 (GSK3) $\beta /$ Tau signalling pathway and/or by attenuating $A \beta$ formation. Thus, their study indicates that ginsenoside Rg1 may be a potential prophylactic drug for AD (116).

Plattner et al noted in their study that the hyperphosphorylation of the microtubule-associated protein Tau is a characteristic feature of neurodegenerative tauopathies, including AD (117). The overactivation of proline-directed kinases, such as cyclin-dependent kinase (CDK)5 and GSK3, has been implicated in the aberrant phosphorylation of Tau at proline-directed sites. The results obtained in the study by Plattner et al prove the role of GSK3 as a key mediator of Tau hyperphosphorylation, whereas CDK5 acts as a modulator of Tau hyperphosphorylation via the inhibitory regulation of GSK3 (117).

Li et al (118) convincingly proved in their study that pretreatment of adult male SD rats with ginsenoside $\mathrm{Rd}(10 \mathrm{mg} / \mathrm{kg}$ for 7 days) or that of cultured cortical neurons (2.5 or $5 \mathrm{~mol} / \mathrm{l}$ for $12 \mathrm{~h}$ ) reduced OKA-induced neurotoxicity and Tau hyperphosphorylation by enhancing the activities of protein phosphatase $2 \mathrm{~A}$. The results of their study implied that ginsenoside Rd protected the SD rats and cultured cortical neurons against OA-induced toxicity (118).

Zhang et al (119) subjected SD rats to focal cerebral ischemia. Treatment with ginsenoside $\mathrm{Rd}$ attenuated the ischemia-induced enhancement of Tau phosphorylation and ameliorated behavioral impairment. Furthermore, they revealed that ginsenoside Rd inhibited the activity of GSK-3 $\beta$, the most important kinase involved in Tau phosphorylation, but enhanced the activity of PKB/Akt, a key kinase suppressing GSK-3 $\beta$ activity (119).

A decrease in the activity of protein phosphatase $2 \mathrm{~A}(\mathrm{PP}-2 \mathrm{~A})$ in the cerebrum of individuals with $\mathrm{AD}$ is another cause of $\tau$-protein hyperphosphorylation. PP-2A is the key serine/threonine phosphatase and presents broad substrate specificity. It is involved in the dephosphorylation of the $\tau$-protein (120). It has been proven that ginsenoside $\mathrm{Rd}$ is capable of activating PP-2A in vitro and in vivo, and thereby reducing the level of $\mathrm{p}$-Tau (121).

It has also been demonstrated that various ginsenosides can reduce the level of $\mathrm{p}$-Tau and prevent the formation of p-Tau (43). However, to date, there is no clear understanding of the mechanisms through which this occurs.
Ginsenoside $\operatorname{Rg} 1$ has been observed to reduce the formation of NFTs in a study on transgenic rats that have increased APP and A $\beta$ production. The authors of that study associated the accumulation of NFTs with brain-cell apoptosis (81). Furthermore, it was shown that ginsenoside Rg1 blocked the stress-apoptotic pathway that was caused by the disruption of the endoplasmic reticulum. The blocking of this pathway was initiated by the inhibition of the expression of IRE-1, factor 2, which is associated with TRAF2 and p-JNK. Moreover, as mentioned above, ginsenoside $\mathrm{Rg} 1$ inhibited apoptosis by increasing the $\mathrm{Bcl}-2 / \mathrm{Bax}$ ratio $(81,119)$.

In another study, it was assumed that the mechanism of NFTs accumulation was mediated by the influence of neprilysin and protein kinase A (PKA) on the phosphorylation of the $\tau$-protein. Ginsenoside $\mathrm{Rg} 1$ reduced the activity and expression of PKA and increased the activity and expression of NEP at the same time, thereby inhibiting $\tau$-protein hyperphosphorylation (70).

\section{Ginsenosides and other factors}

Elevated levels of $\mathrm{A} \beta$ can inhibit the expression of neurotrophic factors, such as BDNF and insulin-like growth factor-1 (IGF-1). It has been found that BDNF is a synaptic-plasticity regulator that is involved in memory and cognitive functions. It plays a role in several events that constitute the pathological cascade in AD (122). A decrease in the level of IGF-1 in the brain is considered an important factor in the development of cognitive impairment and $A \beta$ deposition (123). Ginsenoside Rg5 is able to increase the expression of BDNF and IGF-1, as shown in a study on a mouse model of AD. Ginsenoside Rg1 has not only been recorded to increase BDNF expression in a transgenic mouse model of $\mathrm{AD}$, but also to activate TrkB, which acts as the BDNF receptor, thereby activating the BDNF/TrkB pathway (75). The effective transcription of BDNF only occurs following the activation of four transcription factors, including CREB (124). In most cases, CREB dysfunction plays a significant role in alterations in BDNF expression. The activation of CREB occurs mainly via phosphorylation at Ser133 by PKA, the activity of which is suppressed in the model of AD induced by $A \beta$. In fact, it has been shown that ginsenoside Rg1 increases the expression of BDNF via the phosphorylation of CREB and the activation of PKA (125).

Bone marrow stem cell (BMSC) transplantation is currently used in the treatment of cerebral ischemic disease. However, this method also presents some disadvantages, such as the low conversion rate of neural cells and weak proliferation ability (126). Ginsenoside Rg1 is a possible therapeutic agent for cerebral ischemia as its molecules are small enough to pass through the blood-brain barrier (127).

Reperfusion in cerebral ischemia can cause a significant disruption to the nervous system, and can increase the water content in the brain and the volume of infarction. Notably, ginsenoside $\mathrm{Rg} 1$ can improve nervous system deficiency, reduce cell apoptosis and increase the sensitivity of neuron-specific cell enolase and the gliofibrillary acidic protein of cells. Moreover, ginsenoside $\operatorname{Rg} 1$ not only significantly increases the protein level of Bcl-2, but also lowers the protein level of Bax (126).

The combined use of ginsenoside Rg1 and BMSC transplantation improves the quality of brain tissue by enhancing 
the neuro-like cell differentiation and the anti-apoptotic effect of ginsenoside $\operatorname{Rg} 1$ in reperfusion injury in cases of cerebral ischemia (126).

Ginsenoside Rg1 has also been found to improve neurological injury conditions by suppressing the expression of aquaporin 4 (127).

It is well known that the inflammation and apoptosis of neurons often occur with reperfusion injury following cerebral ischemia. Kashour et al clearly indicated in their study that the expression of dominant-negative late Simian virus 40 transcription factor (LSF) led to a marked increase in staurosporine-induced cell death that was significantly blocked by hAPPwt. These effects of Alzheimer's APP were accompanied by LSF nuclear translocation and dependent gene transcription. The activation of LSF is dependent on the expression of hAPPwt and is inhibited by the expression of dominant-negative forms of either phosphoinositide 3-kinase or Akt. These results demonstrate that LSF activation is required for the neuroprotective effects of APP via PI3K/Akt signalling (111).

Chem-oxygenase-1 (HO-1) is one of the downstream effectors of PPAR $\gamma$. The PPAR $\gamma / \mathrm{HO}-1$ signalling system can inhibit apoptosis and inflammation. The association between ginsenoside $\operatorname{Rg} 1$ and the PPAR $\gamma / \mathrm{HO}-1$ signalling system in cerebral ischemic reperfusion injury has been investigated. Li et al (128) hypothesized that the neuroprotective effects of ginsenoside $\operatorname{Rg} 1$ occur through PPAR $\gamma$ signaling in the ischemic brain. They demonstratyed that $\mathrm{Rg} 1$ markedly increased PPAR $\gamma$ expression in ischemic rats and in the cortical neurons of cerebral cortical neuron ischemic injury model rats. They also found that the selective PPAR $\gamma$ antagonist, GW9662, reduced PPAR $\gamma$ expression, suggesting that $\operatorname{Rg} 1$ may be a potent PPAR $\gamma$ agonist.

With the use of the middle cerebral artery occlusion rat model with cerebral ischemia/reperfusion injury, Li et al (128) also observed that $\operatorname{Rg} 1$ effectively reduced neurological disorders and swelling of the brain in cerebral ischemic injury. These results are in accordance with those of other studies which demonstrated the effectiveness of Rg1 as a neuroprotector in various models of cerebral ischemic injury, including neurological deficits $(129,130)$.

In addition, ginsenoside $\mathrm{Rg} 1$ has not only been found to reduce the levels of IL- $1 \beta$, TNF- $\alpha$ and high mobility group box protein 1 (HMGB1), but also to suppress the expression of cleaved caspase-3, cleaved caspase- 9 and the receptor for advanced glycation end products (RAGE) in rat models (129). The infarct volume of the cerebrum and the permeability of the blood-brain barrier decreases with cerebral ischemic disease following exposure to ginsenoside Rg1. Ginsenoside Rg1 may attenuate neurological injury, the brain infarct volume and the blood-brain barrier permeability induced by focal cerebral ischemia in rats, and its neuroprotective mechanism is related to the downregulation of protease activated receptor-1 (PAR-1) expression. The permeability of the blood-brain barrier also increases with an increase in PAR-1 expression (131).

Moreover, astrocytes play an important role in the ischemic death of neurons. Although ginsenoside Rg1 does not alter the viability of astrocytes, its effect can weaken apoptosis and inhibit the intracellular overload of $\mathrm{Ca}^{2+}$ in astrocytes. In addition, ginsenoside Rg1 can reduce the loss of the transmembrane potential of the mitochondria and ROS production in astrocytes (132).

Metabolomic analyses have been performed in a number of studies, and substances whose level varied in the $A D$ model have been identified and recovered under the action of various ginsenosides. In a previous study, a total of 10 potential biomarkers that were associated with the metabolism of lecithin, amino acids, and sphingolipids were identified in mice with AD based on metabolomics. These biomarkers in the plasma of mice with $\mathrm{AD}$ were disrupted. Following treatment with ginsenoside $\mathrm{Re}$, the disrupted metabolic profiling was restored back to control-like levels, indicating that the protective effect of ginsenoside Re in $\mathrm{AD}$ was exerted through these pathways (133). In that study (133), the levels of hexadecasphinganine and phytosphingosine were both decreased in the plasma of mice with $\mathrm{AD}$ as compared to the control mice. Following treatment with ginsenoside Re, the levels of these two metabolites were significantly elevated. Thus, the results suggest that mice with AD have impaired sphingolipid metabolism, and therefore plasma sphingolipids can also be utilized as indicators of therapeutic response. The therapeutic effects of ginsenoside Re on mice with $\mathrm{AD}$ are exerted through the modulation of sphingolipid metabolic processes (133).

Ginsenosides Rg1 and Rb1 increase the concentrations of tryptophan, di-hydrosphingosine ( $\operatorname{Rg} 1$ only), various lysosfatidylcholines (C22: 6, C20: 4, C18: 2, C16: 0, C18: 1 and C18: 0), and lower the levels of phenylalanine (53). Ginsenoside $\mathrm{Rg} 2$ increases the concentrations of hypoxanthine, dihydrosphingosine, hexadecasphinganine and lysosfatidylcholine C16: 0 and C18: 0 (73).

A comparative proteomics analysis was performed on a model of AD using the stable isotope labelling by amino acids in cell culture (SILAC) in order to examine the potential defence mechanisms of ginsenoside Rb1. Forty proteins were found that exhibited significant changes after the treatment of cells, into which A $\beta$ had previously been introduced, with ginsenoside $\mathrm{Rb} 1$. As a result, the authors suggested that proteins, such as adenylyl cyclase associated protein 1 , the isoform 2 , the subunit $\beta$ F-actin-closure protein and the subunit of the mitochondrial receptor TOM40, can act as potential biomarkers and regulatory proteins in protector mechanisms that prevent $\mathrm{AD}$ (134).

\section{Ginsenosides and individuals with Alzheimer's disease}

The American National Institute of Neurological and Communication Disorders and Stroke, and the Alzheimer's Disease Association formed the most commonly used set of criteria for the diagnosis of AD. The following neuropsychological tests are therefore widely used to assess cognitive impairment: i) Mini-Mental Status Examination (MMSE); ii) $\mathrm{AD}$ assessment scale (ADAS), which includes the cognitive subscale (ADAS-cog) and the non-cognitive subscale (ADAS-non-cog); iii) 'Frontal Assessment Battery' (FAB) Test and iv) clinical dementia rating (CDR) (135).

Studies have been conducted to assess the effects of ginseng components on the course of AD in humans. The clinical efficacy of heat-processed ginseng with the novel ginsenoside 
complex, SG-135, was confirmed in relation to cognitive function in patients with moderately severe disease. An increase in the ADAS-cog, ADAS-non-cog and MMSE tests has been proven to occur as a function of the SG-135 dose (136).

The groups treated with the higher dose exhibited an improvement in cognitive improvement as early as at 12 weeks, which was sustained for 24 weeks of follow-up. The SG-treated patients also exhibited an improving trend over time. Improvement in cognitive function following SG treatment supports the findings that ginsenosides $\operatorname{Rg} 3(\mathrm{R}), \operatorname{Rg} 3(\mathrm{~S})$ and $\mathrm{Rg} 5 / \mathrm{Rk} 1$ exert memory-enhancing effects due to their neuroprotective actions against excitotoxicity (136).

Yang et al (137) investigated the neuroprotective and antioxidant effects of ginsenoside compound $\mathrm{K}(\mathrm{CK})$ on a mouse model of memory impairment induced by scopolamine hydrobromide. It should be noted that protopanaxadiol saponin is degraded by the intestinal flora into ginsenoside CK $(20-O-\beta-\mathrm{D}$ glucopyranosyl-20-(S)-protopanaxadiol) (CK). The role of CK in the regulation of $A \beta$ and its ability to activate the $\mathrm{Nrf2} /$ Keap1 signaling pathway have also been studied due to their great significance for AD. It has been proven that ginsenoside CK improves memory function, inhibits the expression of $A \beta$ and activates the Nrf2/Keap1 signaling pathway in animals exposed to scopolamine. Based on these results, Yang et al (137) concluded that ginsenoside CK can improve memory function by regulating $\mathrm{A} \beta$ aggregation and facilitating the transduction of the Nrf2/Keap1 signaling pathway, thereby reducing oxidative damage to neurons and inhibiting neuronal apoptosis. $\mathrm{Rg} 3$ is the most effective ginsenoside having an A $\beta$-lowering effect, and the effect is correlated with the dose of Rg3. Similarly, Heo et al observed dose-related cognitive improvements following SG treatment (136).

Of note, Korean white ginseng root powder was previously shown to improve the performance of the ADAS-cog and MMSE tests. However, the ADAS-non-cog test scores remained unaltered, and the test scores evened out with those of the control group after the drug was discontinued (138). An increase in indicators was only found in the ADAS-cog and CDR tests, while the indicators of the ADAS-non-cog and MMSE tests were the same as those of the control group in a similar study using Korean red ginseng (KRG) root powder (139). Moreover, electroencephalography was used to assess the effectiveness of KRG root powder in relation to cognitive functions. An increase in relative alpha power was found in patients with AD who were treated with KRG root powder, which indicates an improvement in the functions of the frontal lobe. The FAB test scores also increased, although the MMSE scores remained unaltered (140).

In a different study, cognitive functions were assessed every 12 weeks, using the ADAS and the Korean version of the Mini-mental status examination (K-MMSE), to investigate maintenance doses of 4.5 and $9.0 \mathrm{~g}$ of KRG per day (141). A significant improvement was observed in groups that took KRG for 24 weeks. The improved MMSE score did not exhibit significant decreases at the 48th and 96th week, in a long-term assessment of the impact effectiveness of KRG. Similar results were obtained in the ADAS-assessment. The maximum improvement was found on the 24th week (141).

In another study, improved cognitive function was demonstrated with KRG treatment as was the sustainability of the achieved clinical goals in patients with AD. Previously, data on the long-term effects of KRG in patients with AD were limited, and studies did not exceed a few months (138), meaning that these shorter-term studies did not exactly indicate whether the effect of ginseng is temporary or whether it is able to continue to suppress the progressive course of AD. The results obtained in the long-term KRG study indicated that the effectiveness of KRG on cognitive function during the course of AD can be maintained for at least 2 years (141).

Several long-term (over 2 years) tests on AChE inhibitors have demonstrated that, although the efficacy of the drugs is evident, they were not able to block or reverse cognitive decline $(142,143)$. The 2-year MMSE decline typically ranged from 2.5 to 4.0 points compared to the initial estimate. The usual picture of cognitive decline shows an initial improvement of 3 or 6 months, and then decreases to baseline over about a year in patients taking conventional medication. The disease then progresses again. By contrast, the ADAS-cog and K-MMSE scores were stable and did not exhibit an obvious decrease at the registration times over 2 years (141). This clinical picture can be explained by the difference in the main mechanisms of action of ginseng and anticholinesterase. The effect of ginseng on cognitive function with underlying specific mechanisms of influence has been considered (144). It is known that ginsenoside Rb1 improves learning and memory in tasks that are dependent on the hippocampus, and that it increases cell survival in the dentate gyrus of the medial and lower hemispheres of the large brain and in the hippocampal subregion CA3 (145). Ginsenoside Rg1 has been observed to weaken $\mathrm{A} \beta_{1-42}$-induced neurotoxicity and $\tau$-hyperphosphorylation, in a dose-dependent manner, at several sites that are associated with AD (146). Moreover, it has been suggested that ginsenoside Rg1 and Rb1 potentiate cholinergic pathways in the central nervous system and it was found that both ginsenosides Rg1 and Rb1 enhance the activity of ChAT and inhibit the activity of AChE, thereby enhancing the function of the cholinergic system (147).

The introduction of $\mathrm{Rg} 1$ and $\mathrm{Rb} 1$ to mice in the post-weaning period has been shown to increase the thickness and density of the cerebral cortex in the CA3 region of the hippocampus, which is believed to modulate synaptic plasticity, regarded as one of the most important learning and memory mechanisms (148).

\section{Conclusion}

We herein present a literature survey on the ginseng components that have exhibited biological activity on the pathogenesis of AD. Information on the effects of ginseng components on the signs of AD is depicted in Table III. The same symptoms that are observed in patients with $\mathrm{AD}$ are artificially created in animal models of $\mathrm{AD}$; the mechanisms that trigger $\mathrm{AD}$ have not yet been confirmed with all possible accuracy. However, BAS found in ginseng can have a significant protective and inhibitory effect on the further development of $\mathrm{AD}$, as shown by the foregoing review and general research data, summarized in Table III. The data obtained in studies on the effects of ginseng components on patients with AD have shown that ginseng preparations can be used for maintenance therapy. 
Table III. Effect of the components of ginseng on the pathogenesis of AD.

\begin{tabular}{l} 
Model AD \\
\hline $\begin{array}{l}\text { Enzyme activity } \\
\text { measurement } \\
\text { (without models) }\end{array}$ \\
Rat PC12 cells; \\
Introduction A $\beta_{25-35}$ \\
Male ICR mice \\
(6 weeks); \\
Intracerebroventricular \\
injection $A \beta_{1-42}$
\end{tabular}

Wistar rats

Streptozocin administration

ICR male mice (7 weeks, 30-33 g); Intragypocampal injection $\mathrm{A} \beta \mathrm{O}$

N2a/APP695 cell line;

Male Sprague-Dawley rats Intragypocampal injection $A \beta_{1-42}$

Female rats with ovaries removed (280-300 g) HT22 hippocampal neuronal cell line expressing ER

Line of neuronal cells of the hippocampus HT22 Human neuroblastoma cells SH-SY5Y
Ginsenoside Rg5

Ginsenosides Rb1, $\mathrm{Rb} 2, \mathrm{Rc}, \mathrm{Re}$,

Rg1 and Rg3

Extract Panax japonicus

Cereboost $^{\mathrm{TM}}$ (extract

Panax quinquefolius)

.


Table III. Continued.

Model AD
Female Wistar rats with
ovaries removed ( 9 months)

12 women with menopause Platelet rich plasma taken

\author{
Female Wistar rats \\ (10 weeks, 260-300 g) \\ Ovarian removal \\ Injection of D-galactose
}

Mice SAP8 (with elevated level APP and $A \beta_{1-42}$ )

Cortical neurons from mouse embryos $\operatorname{Tg} 2576$

Neuronal differentiated mouse embryonic stem cells Transgenic APP/PSI mice

Human neuroblastoma cells SH-SY5Y

Transgenic mice (with elevated level $\mathrm{A} \beta_{1-42}$ )

\section{Cell PC12}

Injection $A \beta_{25-35}$

Cells PC12

Injection of glutamate

Primary cortical neurons Sprague-Dawley rats Injection $\mathrm{A}_{\beta 25-35}$

$$
\text { Ginsenoside Rg1 }
$$

Ginsenoside Rg1

Saponins from

Panax notoginseng

Ginsenoside Rh2

Ginsenoside $\operatorname{Rg} 3$

Gintonin (glyco-lipoprotein fraction of ginseng extract)

Ginsenoside Rg2

Ginsenoside $\operatorname{Rg} 2$

Ginsenoside Rb1 $\downarrow$ Level $\mathrm{A} \beta_{1-42}$;

$\uparrow$ Level p-ERK and ERK;

$\uparrow$ Level p-AKT and AKT;

$\uparrow$ Expression p-ER $\alpha$ and $\mathrm{ER} \alpha$;

$\uparrow$ Level sAPP $\alpha$;

$\downarrow$ Level A $\beta_{1-42}$;

$\uparrow$ Activity $\alpha$ - secretase;

$\uparrow$ Level p-ERK1/2, without affecting the overall level ERK1/2;

$\uparrow$ Cognitive abilities of rats;

$\downarrow$ Generation $\mathrm{A} \beta_{1-42}$;

$\downarrow$ Activity caspase-3;

$\downarrow$ Cell apoptosis;

$\uparrow$ Expression ADAM10;

$\downarrow$ Expression BACE1;

$\uparrow$ Activity $\alpha$-secretase;

$\downarrow$ Activity BACE1;

Activity of $\gamma$-secretase was not altered

$\uparrow$ Cognitive abilities of mice;

$\downarrow$ Level A $\beta_{1-42}$;

Activity of $\alpha$-secretase and BACE1 was not altered;

$\uparrow$ Level sAPP $\alpha$;

Total level of APP was not altered;

$\uparrow$ Cholesterol level in neurons;

$\downarrow$ Level A $\beta_{1-42}$;

$\uparrow$ Activity of PI4KII $\alpha$;

$\uparrow$ Activity LPAR

$\downarrow$ Level A $\beta_{1-42}$;

$\uparrow$ Level sAPP $\alpha$;

$\downarrow$ Cytotoxicity A $\beta_{1-42}$ in cells;

$\uparrow$ Cognitive abilities of mice;

$\downarrow$ Microglial activation;

$\uparrow$ Cell viability;

$\downarrow$ Level LDH;

$\downarrow$ Level ROS;

$\downarrow$ Intracellular level $\mathrm{Ca}^{2+}$;

$\downarrow$ Activity of caspase-3;

$\uparrow$ Ratio Bcl-2/Bax;

$\uparrow$ Level p-Akt;

$\downarrow$ Cytotoxicity $\mathrm{A} \beta_{1-42}$ in cells;

$\uparrow$ Neuroprotective properties;

$\downarrow$ Intracellular level $\mathrm{Ca}^{2+}$;

$\downarrow$ Level MDA;

$\downarrow$ Level NO;

$\downarrow$ Level A $\beta_{1-42}$;

$\downarrow$ Expression caspase-3;

$\downarrow$ Expression calpain II;

$\downarrow$ Level p-tau;

$\downarrow$ Cytotoxicity $A \beta_{25-35}$ in cells;

$\downarrow$ Level and expression CDK5

$\downarrow$ Calpain activity;

$\downarrow$ Intracellular level $\mathrm{Ca}^{2+}$;
Kang et al (64)

Authors/(Refs.)

Shi et al (53)

Zhang et al (54)

Huang et al (55)

Qiu et al (58)

Hwang et al (89)

Cui et al (95)

Li et al (96)

Chen et al (97) 
Table III. Continued.

Model AD
SD rats
$\mathrm{A} \beta_{25-35}$ injection
Female Wistar rats

(3 months),

Tg APP/PSI rats

Male Sprague-Dawley rats Intragypocampal injection A $\beta_{1-42}$ Liu J
Primary cortical neurons from the brain of newborn (0-24 h) mice;

Female rats (260-280 g); Injection of D-galactose and aluminum chloride

Cortical cortical neurons (PC12 cells)

APP transgenic mice (10 months)

Male Wistar rats (3-4 weeks, 250-300 g) Intracerebroventricular injection $A \beta_{1-42}$

Female Wistar rats (260-280 g); Injection of D-galactose and aluminum chloride
Panax ginseng

C.A. Meyer

root extract

(aged 4 years)

Radix Notoginseng

flavonol glycoside

(RNFG), quercetin

3-O- $\beta$-D-xylo-

pyranosyl- $\beta$-D-

galactopyranoside

Ginsenoside Rd

Ginsenoside Rb1

Panax ginseng C.A.

Meyer root extract

(age 4 years)
Research results

Authors/(Refs.)

Quan et al (98)

$\downarrow$ Current density through high-threshold calcium channels through MAPK;

Mu et al (81)

$\downarrow$ Level of $A \beta_{1-42}$;

$\downarrow$ Apoptosis;

$\downarrow$ Expression of IRE-1;

$\downarrow$ Expression of TRAF2;

$\downarrow$ Expression of p-JNK;

$\uparrow$ Cognitive abilities of rats;

$\uparrow$ Neuroprotective properties;

$\downarrow$ Cytotoxicity of $\mathrm{A} \beta_{1-42}$;

$\downarrow$ Expression IL-1 $\beta$;

$\downarrow$ Level and expression of IL-6;

$\uparrow$ Level and expression of IL-10;

$\downarrow$ Level and expression of TNF- $\alpha$;

$\uparrow$ Expression of HSP70;

$\downarrow$ Ratio of GSSG/GSH;

$\downarrow$ Expression of caspase-3;

$\uparrow$ Survival rate

Li et al (103)

$\downarrow$ Neuronal apoptosis in vitro;

$\uparrow$ Ratio of expression p-PKA/PKA

and p-CREB/CREB;

$\downarrow$ Concentration of MDA;

$\downarrow$ Concentration of NO;

$\uparrow$ Ratio of Bcl-2/Bax;

$\downarrow$ Expression of caspase-3;

$\downarrow$ Level of $\mathrm{p}$-Tau;

$\uparrow$ Activity of SOD;

$\downarrow$ Activity of NOS2 and NOS;

$\uparrow$ Level of cAMP;

$\downarrow$ Cytotoxicity $\mathrm{A} \beta_{1-42}$ in cells;

$\downarrow$ Level of $\mathrm{A} \beta_{1-42}$;

$\downarrow$ Level of ROS;

Choi et al (104)

$\uparrow$ Cognitive abilities of mice;

Liu et al (88)

$\downarrow$ Expression and activity of NF- $\mathrm{B}$ p65;

$\downarrow$ Level of IL-1 $\beta$;

$\downarrow$ Level of TNF- $\alpha$; d

$\downarrow$ Level of IL-6;

$\downarrow$ Level of IL-10;

$\uparrow$ Cognitive abilities of rats;

Wang et al (85)

$\downarrow$ Level of $A \beta_{1-42} ; 0$

$\downarrow$ Level of COX2;

$\uparrow$ Level of iNOS;

$\uparrow$ Cognitive abilities of rats;

$\downarrow$ Quantity A $\beta_{1-42}$;

$\downarrow$ Quantity p-tau;

$\uparrow$ Activity of

PI3K/Akt signalling pathway; 
Table III. Continued.

Model AD
Male Sprague-Dawley rats
(200-240 g)
Intracerebroventricular
injection OKA
Male Sprague-Dawley rats
(270-320 g)
Artificial cerebral ischemia
Male Sprague-Dawley rats
Cortical neurons
Injection OKA

Male Wistar rats weighting 180-220 g Injection of D-galactose (D-gal) with $\mathrm{AlCl} 3$ (Al) for 60 days

\begin{abstract}
Male SAMP8 and SAMR1 mice (6 months)
\end{abstract}

12-Month-old mice (18-22 g);

Intracerebroventricular injection

Male Kunming mice

(12-month-old mice, 18-22 g)

Intragypocampal

injection $A \beta_{1-42}$

Male mice APP/PSI

and $\mathrm{C} 57 \mathrm{BL} / 6 \mathrm{j}$

\section{SH-SY5Y cells}

Exposure to $A \beta_{25-35}$

40 Individuals with AD

$(72.9 \pm 9.4$ years old $)$

Treatment
Ginsenoside Rg1
Ginsenoside Rd
Ginsenoside Rd

Ginsenoside Rg1

Ginseng extract

Ginsenoside Rg1

Ginsenoside Re

Ginsenosides Rg1 and $\mathrm{Rb} 1$

Ginsenosides Rg1 and $\operatorname{Rg} 2$

Ginsenoside Rb1 SILAC

Ginsenoside complex SG-135
Research results

Authors/(Refs.)

$\downarrow$ Cognitive abilities of rats;

$\downarrow$ Level of p-Tau;

$\uparrow$ Level of GSK3 $\beta$-Tyr216;

$\uparrow$ Level of $\mathrm{A} \beta_{1-42}$;

$\uparrow$ Cognitive abilities of mice;

$\downarrow$ Level p-Tau;

$\uparrow$ Activity of AKT

$\uparrow$ Weight of rats without changing morphology in the hippocampus and cerebral cortex;

$\uparrow$ Neuroprotective properties in vitro;

$\downarrow$ Phosphorylation of Tau in vitro;

$\uparrow$ Activity of PP-2A

$\uparrow$ Memory function of mice;

$\downarrow$ Level p-Tau;

$\downarrow$ Level of $\mathrm{A} \beta_{1-42}$;

Expression of APP was not altered;

$\downarrow$ Level of APP;

$\uparrow$ Expression of BDNF;

$\uparrow$ Level of p-TrkB;

$\uparrow$ Cognitive abilities of mice;

$\downarrow$ Neuronal death;

$\downarrow$ Level of $\mathrm{A} \beta_{1-42}$;

$\downarrow$ Level of p-Tau;

$\uparrow$ Blood glycine level;

$\uparrow$ Level of 5-hydroxytryptamine in blood;

$\uparrow$ Cognitive abilities of mice;

$\downarrow$ Level of A $\beta_{1-42}$;

$\downarrow$ Level of PKA RII $\alpha$;

$\uparrow$ Level of p-CREB;

$\uparrow$ Level of BDNF

$\uparrow$ Cognitive abilities of mice;

$\uparrow$ Hexadecanasphinganine and phytosphingosine concentrations;

$\uparrow$ Phenylalanine concentration;

$\downarrow$ Tryptophan concentration

$\uparrow$ Level of LPC;

$\downarrow$ Level of phenylalanine;

$\uparrow$ Tryptophan level;

$\uparrow$ Dihydrosphingosine for Rg1

(unaltered level for Rb1)

$\uparrow$ Cognitive abilities of mice;

$\downarrow$ Level A $\beta_{1-42}$;

$\uparrow$ Hypoxanthine level;

$\uparrow$ Level LPC;

Change in metabolic profile for sphingolipids

Change in levels of 40 proteins in response to $\mathrm{Rb} 1$ pretreatment in $\beta$-amyloid-treated cells

$\uparrow$ Indicators ADAS-cog;

$\uparrow$ Indicators ADAS-non-cog;

$\uparrow$ Indicators K-MMSE
Song et al $(118=6)$

Zhang et al (119)

Li et al (121)

Li et al (75)

Zhang et al (43)

Shi et al (125)

Li et al (133)

Li et al (74)

Li et al (73)

Hwang et al (134)

Heo et al (136) 
Table III. Continued.

\begin{tabular}{|c|c|c|c|}
\hline Model AD & Treatment & Research results & Authors/(refs.) \\
\hline $\begin{array}{l}97 \text { Individuals with AD } \\
\text { ( } 47-83 \text { years old) }\end{array}$ & $\begin{array}{l}\text { Ginseng root powder } \\
\text { (age } 6 \text { years) }\end{array}$ & $\begin{array}{l}\uparrow \text { indicators MMSE; } \\
\uparrow \text { indicators ADAS-cog; } \\
\text { Indicators ADAS-non-cog did not change } \\
\text { The MMSE and ADAS-cog rates } \\
\text { were the same as in the control group } \\
12 \text { weeks after discontinuation of the } \\
\text { ginseng drug }\end{array}$ & Lee et al (138) \\
\hline $\begin{array}{l}61 \text { Individuals with AD } \\
\text { (50-80 years old) }\end{array}$ & $\begin{array}{l}\text { Red Korean Ginseng } \\
\text { root powder } \\
\text { (age } 6 \text { years) }\end{array}$ & $\begin{array}{l}\uparrow \text { Indicators ADAS-cog; } \\
\uparrow \text { Indicators CDR; } \\
\text { Indicators ADAS-non-cog } \\
\text { were not altered; } \\
\text { Indicators MMSE } \\
\text { were not altered }\end{array}$ & Heo et al (139) \\
\hline $\begin{array}{l}14 \text { Individuals with AD } \\
(74.93 \pm 7.63 \text { years old })\end{array}$ & $\begin{array}{l}\text { Red Korean } \\
\text { Ginseng root powder } \\
\text { (age } 6 \text { years) }\end{array}$ & $\begin{array}{l}\uparrow \text { test results FAB; } \\
\uparrow \text { the power of the alpha rhythm } \\
\text { in the right temporal, } \\
\text { parietal and occipital regions of the brain; } \\
\text { K-MMSE did not change }\end{array}$ & Heo et al (140) \\
\hline $\begin{array}{l}61 \text { Individuals with AD } \\
\text { (60-80 years old) }\end{array}$ & $\begin{array}{l}\text { Red Korean Ginseng } \\
\text { root powder } \\
\text { (age } 6 \text { years) }\end{array}$ & $\begin{array}{l}\uparrow \text { indicators ADAS-cog; } \\
\uparrow \text { indicators MMSE }\end{array}$ & Heo et al (141) \\
\hline
\end{tabular}

AD, Alzheimer's disease; Ach, Acetylcholine; Ache, acetylcholinesterase; BChE, butyrylcholinesterase; APP, amyloid precursor protein; sAPP $\alpha$, water soluble $\alpha$-amyloid; ER, estrogen receptor; PI4KII $\alpha$, phosphatidylinositol-4-kinase 2 $\alpha$; LPC, lysophosphatidylcholines; TrkB, tyrosine receptor kinase B; ADAM10, a-secretase a disintegrin and metallopeptidase domain 10; ROS, reactive oxygen species; TNF- $\alpha$, tumour necrosis factor $\alpha$; NO, nitric oxide; NOS2, synthase nitric oxide 2, induced; SD, Sprague-Dawley; CDK5, cyclin-dependent kinase 5; GSK3, glycogen synthase kinase 3; TRAF2; tumour necrosis factor receptor 2; p-JNK, phosphorylated-c-Jun $\mathrm{N}$-terminal protein kinase associated with apoptosis; IGF-1, insulin-like growth factor-1; cAMP, cyclic adenosine monophosphate; CREB, cAMP response-element-binding protein; SILAC, stable isotope labelling of amino acids in a cell culture; MMSE, Mini-Mental Status Examination; K-MMSE Korean MMSE; CDR, Clinical Evaluation of Dementia; PPAR, peroxisome proliferator activated receptor.

At the same time, a drug that consists of correctly selected ratios of the various components of ginseng is likely to be more effective than a simple ginseng root extract. However, the creation of such a drug will entail large-scale studies on the effects of individual components of ginseng on patients with AD.

\section{Acknowledgements}

The authors would like to thank Dr Muhammad Amjad Nawaz from SEC of Nanotechnology, Far Eastern Federal University, Vladivostok, Russian Federation for his assistance with the copy-editing of the manuscript and for correcting the final proofs.

\section{Funding}

No funding was received.

\section{Availability of data and materials}

Data sharing is not applicable to this review article, as no datasets were generated or analyzed during the current study.

\section{Authors' contributions}

MPR, AT and KSG conceptualized and designed the study. MPR, DAS and AMZ collected, organized and drafted the information. AEN and GC collected information on the introduction and history of ginseng. MPR and VVV collected data and prepared tables. MPR, KSG and AEN wrote the manuscript. KSG, AMT and DAS revised the manuscript critically and advised revisions. All authors have read and approved the manuscript.

\section{Ethics approval and consent to participate}

Not applicable.

\section{Patient consent for publication}

Not applicable.

\section{Competing interests}

DAS is the Editor-in-Chief for the journal, but had no personal involvement in the reviewing process, or any influ- 
ence in terms of adjudicating on the final decision, for this article.

\section{References}

1. Alzheimer A, Stelzmann RA, Schnitzlein HN and Murtagh FR An English translation of Alzheimer's 1907 paper, 'Uber eine eigenartige Erkankung der Hirnrinde'. Clin Anat 8: 429-431, 1995.

2. Hardy J and Allsop D: Amyloid deposition as the central event in the aetiology of Alzheimer's disease. Trends Pharmacol Sci 12: 383-388, 1991.

3. Donev R, Kolev M, Millet B and Thome J: Neuronal death in Alzheimer's disease and therapeutic opportunities. J Cell Mol Med 13: 4329-4348, 2009.

4. Liu Z, Li T, Li P, Wei N, Zhao Z, Liang H, Ji X, Chen W, Xue $M$ and Wei J: The ambiguous relationship of oxidative stress, tau hyperphosphorylation, and autophagy dysfunction in Alzheimer's disease. Oxid Med Cell Longev 2015: 352723, 2015.

5. Hernández F and Avila J: Tauopathies. Cell Mol Life Sci 64: 2219-2233, 2007.

6. Brekhman II, Dardymov IV and Dobriakov II: On the pharmacology of individual glycosides from the roots of Panax ginseng C.A. Mey. Farmakol Toksikol 29: 167-171, 1966 (In Russian).

7. Elyakov G, Strigina L, Khorlin A and Kochetkov H: Glycosides of ginseng (Panax ginseng C. A. Mey). Bulletin of the Academy of Sciences of The USSR, Division of Chemical Science. Vol 11, Issue 6, pp1055-1055, 1p, 1962. https://searchworks.stanford. edu/articles/edb 72505988 .

8. Brekhman II: Ginseng. Government publisher of medicine literature. Medgiz, Saint Petersburg, pp 3-163, 1957 (Translated from Russian). http://moodle.pharmi.uz/library/books/Pyc/ Кўшимча\%20адабиётлар/Жень-шень.pdf.

9. Fischer FEL and Meyer CA: Enumeratio plantarum novarum a cl. Schrenk lectarum [Flora change from Cl. Schrenk Lectarum]. Petropoli Publishers, 1841-1842.

10. Arsenyev VK: Myths, legends, traditions, and fables of peoples of Far East. Monograph Series, International Institute of Ethnolinguistic and Oriental Studies (IIEOS), ISSN 1230-3283; 10, ISBN 83-902273-4-7, 1995.

11. Przhevalsky N: Mongolia, The Tangut Country and the Solitudes of Northern Tibet. Translated by E.D. Morgan. Editor (Yule H). London: Sampson Low, Marston, Searle \& Rivington, 2; 24, 1876.

12. Maak R: Journey through the Ussuri river valley. The Siberian Department of the Imperial Russian Geographical Society, 1-2. V. Bezobrazov and Co Printers, Saint Petersburg, 1861.

13. Maximowicz CJ: Diagnoses des nouvelles plantes du Japon et de la Mandjourie [Diagnoses of the new plants of Japan and Mandjourie]. In: Bulletin de l'Academie Imperiale des Sciences de St. Petersbourg. Tome dix-huitieme. Saint Petersbourg, XII decade, $p$ 41.1873.

14. Komarov VL: Coniferae of Manchuria. Trudy Imp. Saint Petersburg. Obsc. 32: 230-241, 1902.

15. Shishkin IK: Studies about the flora of Iman River. Materials of the Vladivostok, Branch of the Russian Geographical Society 5: 128-130, 1930.

16. Gutnikova ZI: Ginseng in Suputinsky reserve. Materials of the Academy of Sciences of the USSR 4: 257-267, 1941.

17. Gutnikova ZI: Preliminary data on the culture of ginseng in the conditions of Suputinsky reserve. Materials of the Academy of Sciences of the USSR 1955.

18. Vysotsky KK: To the question of the biology of wild ginseng. Main Directorate of USSR Reserves 7: 254-262, 1940.

19. Bayanova VB: Conditions of ginseng growth in the 'Kedrovaya Pad' reserve. Materials of the mountain taiga station of the Academy of Sciences of the USSR 4: 217-231, 1941.

20. Kurentsova GE: Medicinal plants of the Soviet Far East. Materials of the mountain taiga station of the Academy of Sciences of the USSR 4: 15-97, 1941.

21. Zakutinsky DI: Pharmacology of ginseng root. Pharmacol Toxicol 7: 13-16, 1944.

22. Burkat ME and Saksonov P: Materials for the pharmacological characterization of ginseng root. Pharmacol Toxicol 10: 7-16, 1947.

23. Kiselev VS: Pharmacological study of the ginseng root. Pharmacol Toxicol 11: 50-57, 1948.

24. Shapiro ML: Ginseng is an active therapeutic drug. J Sov Med 6: $17-19,1947$

25. Kuzminskaya RA: Treatment of vegetative dystonia with ginseng root. Neuropathol Psych 2: 62-63, 1949.
26. Buturlin VV: The use of ginseng root in clinical practice. Sov Med 5: 34-36, 1950.

27. Brekhman II and Dardymov IV: Pharmacological investigation of glycosides from ginseng and eleutherococcus. Lloydia 32: 46-51, 1969.

28. Elyakov GB, Strigina LI, Uvarova NI, Vaskovsky VE, Dzizenko AK and Kochetkov NK: Glycosides from ginseng roots. Tetrahedron Lett 5: 3591-3597, 1964.

29. Elyakov GB, Strigina LI and Kochetkov NK: Glycosides from ginseng roots. VI. Structure of the carbohydrate chain of panaxoside A. In: Chemistry of Natural Compounds. Vol. 1, Issue 3, pp114-116, 1965.

30. Chen Y, Sun J, Fang L, Liu M, Peng S, Liao H, Lehmann J and Zhang Y: Tacrine-ferulic acid-nitric oxide (NO) donor trihybrids as potent, multifunctional acetyl- and butyrylcholinesterase inhibitors. J Med Chem 55: 4309-4321, 2012.

31. Geula C and Mesulam MM: Cholinesterases and the pathology of Alzheimer disease. Alzheimer Dis Assoc Disord 9 (Suppl 2): 23-28, 1995.

32. Wilkinson DG, Francis PT, Schwam E and Payne-Parrish J: Cholinesterase inhibitors used in the treatment of Alzheimer's disease: The relationship between pharmacological effects and clinical efficacy. Drugs Aging: 21, 453-478, 2004.

33. Raschetti R, Albanese E, Vanacore N and Maggini M: Cholinesterase inhibitors in mild cognitive impairment: A systematic review of randomised trials. PLoS Med 4: e338, 2007.

34. Collins LE, Paul NE, Abbas SF, Leser CE, Podurgiel SJ, Galtieri DJ, Chrobak JJ, Baqi Y, Müller CE and Salamone JD: Oral tremor induced by galantamine in rats: A model of the parkinsonian side effects of cholinomimetics used to treat Alzheimer's disease. Pharmacol Biochem Behav 99: 414-422, 2011.

35. Ikonomovic MD, Mufson EJ, Wuu J, Bennett DA and DeKosky ST: Reduction of choline acetyltransferase activity in primary visual cortex in mild to moderate Alzheimer's disease. Arch Neurol 62: 425-430, 2005.

36. Choi RJ, Roy A, Jung HJ, Ali MY, Min BS, Park $\mathrm{CH}$, Yokozawa T, Fan TP, Choi JS and Jung HA: BACE1 molecular docking and anti-Alzheimer's disease activities of ginsenosides. J Ethnopharmacol 190: 219-230, 2016.

37. Li S, Liu C, Liu C and Zhang Y: Extraction and in vitro screening of potential acetylcholinesterase inhibitors from the leaves of Panax japonicus. J Chromatogr B Analyt Technol Biomed Life Sci 1061-1062: 139-145, 2017.

38. Shin K, Guo H, Cha Y, Ban YH, Seo W, Choi Y, Kim TS, Lee SP, Kim JC, Choi EK, et al: Cereboost ${ }^{\mathrm{TM}}$, an American ginseng extract, improves cognitive function via up-regulation of choline acetyltransferase expression and neuroprotection. Regul Toxicol Pharmacol 78: 53-58, 2016.

39. Lee MR, Yun BS, Liu L, Zhang DL, Wang Z, Wang CL, Gu LJ, Wang CY, Mo EK and Sung CK: Effect of black ginseng on memory improvement in the amnesic mice induced by scopolamine. J Ginseng Res 34: 51-58, 2010.

40. Wang Q, Sun LH, Jia W, Liu XM, Dang HX, Mai WL, Wang N, Steinmetz A, Wang YQ and Xu CJ: Comparison of ginsenosides $\mathrm{Rg} 1$ and $\mathrm{Rb} 1$ for their effects on improving scopolamine-induced learning and memory impairment in mice. Phytother Res 24: $1748-1754,2010$

41. Chu S, Gu J, Feng L, Liu J, Zhang M, Jia X, Liu M and Yao D: Ginsenoside Rg5 improves cognitive dysfunction and beta-amyloid deposition in STZ-induced memory impaired rats via attenuating neuroinflammatory responses. Int Immunopharmacol 19: 317-326, 2014.

42. Choi JG, Kim N, Huh E, Lee H, Oh MH, Park JD, Pyo MK and Oh MS: White ginseng protects mouse hippocampal cells against amyloid-beta oligomer toxicity. Phytother Res 31: 497-506, 2017.

43. Zhang Y, Pi Z, Song F and Liu Z: Ginsenosides attenuate d-galactose- and AlCl3-induced spatial memory impairment by restoring the dysfunction of the neurotransmitter systems in the rat model of Alzheimer's disease. J Ethnopharmacol 194: 188-195, 2016.

44. Karp G (ed): Cell and Molecular Biology: Concepts and Experiments. 6th edition. John Wiley \& Sons, New York, NY, 2009.

45. Vassar R, Bennett BD, Babu-Khan S, Kahn S, Mendiaz EA, Denis P, Teplow DB, Ross S, Amarante P, Loeloff R, et al: Beta-secretase cleavage of Alzheimer's amyloid precursor protein by the transmembrane aspartic protease BACE. Science 286 : 735-741,1999.

46. Ohnishi S and Takano K: Amyloid fibrils from the viewpoint of protein folding. Cell Mol Life Sci 61: 511-524, 2004. 
47. Fahrenholz F: Alpha-secretase as a therapeutic target. Curr Alzheimer Res 4: 412-417, 2007.

48. Gubandru M, Margina D, Tsitsimpikou C, Goutzourelas N, Tsarouhas K, Ilie M, Tsatsakis AM and Kouretas D: Alzheimer's disease treated patients showed different patterns for oxidative stress and inflammation markers. Food Chem Toxicol 61 209-214, 2013.

49. Cao G, Su P, Zhang S, Guo L, Zhang H, Liang Y, Qin C and Zhang W: Ginsenoside Re reduces $A \beta$ production by activating PPAR $\gamma$ to inhibit BACE1 in N2a/APP695 cells. Eur J Pharmacol 793: 101-108, 2016.

50. Quan Q, Wang J, Li X and Wang Y: Ginsenoside Rg1 decreases $\mathrm{A} \beta_{1-42}$ level by upregulating PPAR $\gamma$ and IDE expression in the hippocampus of a rat model of Alzheimer's disease. PLoS One 8 e59155, 2013

51. Yan X, Hu G, Yan W, Chen T, Yang F, Zhang X, Zhao G and Liu J: Ginsenoside Rd promotes non-amyloidogenic pathway of amyloid precursor protein processing by regulating phosphorylation of estrogen receptor alpha. Life Sci 168: 16-23, 2017.

52. Shi C, Zheng DD, Fang L, Wu F, Kwong WH, and Xu J: Ginsenoside Rg1 promotes nonamyloidogenic cleavage of APP via estrogen receptor signaling to MAPK/ERK and PI3K/Akt. Biochim Biophys Acta 1820: 453-460, 2012.

53. Shi C, Na N, Zhu X and Xu J: Estrogenic effect of ginsenoside $\mathrm{Rg} 1$ on APP processing in post-menopausal platelets. Platelets 24: $51-62,2013$.

54. Zhang X, Wang J, Xing Y, Gong L, Li H, Wu Z, Li Y, Wang J, Wang Y, Dong L and Li S: Effects of ginsenoside Rg1 or $17 \beta$-estradiol on a cognitively impaired, ovariectomized rat model of Alzheimer's disease. Neuroscience 220: 191-200, 2012.

55. Huang J, Wu D, Wang J, Li F, Lu L, Gao Y and Zhong Z: Effects of Panax notoginseng saponin on $\alpha, \beta$, and $\gamma$ secretase involved in $\mathrm{A} \beta$ deposition in SAMP8 mice. Neuroreport 25 : 89-93, 2014.

56. Zetterberg H, Alexander DM, Spandidos DA and Blennow K Additional evidence for antagonistic pleiotropic effects of APOE. Alzheimers Dement 5: 75, 2009.

57. Endres K and Fahrenholz F: Upregulation of the $\alpha$-secretase ADAM10-risk or reason for hope? FEBS J 277: 1585-1596, 2010.

58. Qiu J, Li W, Feng SH, Wang M and He ZY: Ginsenoside Rh2 promotes nonamyloidgenic cleavage of amyloid precursor protein via a cholesterol-dependent pathway. Genet Mol Res 13: 3586-3598, 2014.

59. Reiss AB and Voloshyna I: Regulation of cerebral cholesterol metabolism in Alzheimer disease. J Investig Med 60: 576-582, 2012.

60. Barrett PJ, Song Y, Van Horn WD, Hustedt EJ, Schafer JM, Hadziselimovic A, Beel AJ and Sanders CR: The amyloid precursor protein has a flexible transmembrane domain and binds cholesterol. Science 336: 1168-1171, 2012.

61. Korade Z and Kenworthy AK: Lipid rafts, cholesterol, and the brain. Neuropharmacology 55: 1265-1273, 2008.

62. Di Paolo G and De Camilli P: Phosphoinositides in cell regulation and membrane dynamics. Nature 443: 651-657, 2006.

63. Balla A and Balla T: Phosphatidylinositol 4-kinases: Old enzymes with emerging functions. Trends Cell Biol 16: 351-361, 2006.

64. Kang MS, Baek SH, Chun YS, Moore AZ, Landman N, Berman D, Hyun Ok Yang, Morishima-Kawashima M, Osawa S, Funamoto S, et al: Modulation of lipid kinase PI4KII $\alpha$ activity and lipid raft association of presenilin 1 underlies $\gamma$-secretase inhibition by ginsenoside (20S) Rg3. J Biol Chem 288: 20868-20882, 2013.

65. Kwik J, Boyle S, Fooksman D, Margolis L, Sheetz MP and Edidin M: Membrane cholesterol, lateral mobility, and the phosphatidylinositol 4,5-bisphosphate-dependent organization of cel actin. Proc Natl Acad Sci USA 100: 13964-13969, 2003

66. Fraering PC, Ye W, Strub JM, Dolios G, LaVoie MJ Ostaszewski BL, van Dorsselaer A, Wang R, Selkoe DJ and Wolfe MS: Purification and characterization of the human $\gamma$-secretase complex. Biochemistry 43: 9774-9789, 2004

67. Barber J: Merck \& Co. terminates Phase III study of verubecestat in prodromal Alzheimer's disease. First Word Farma, Feb 13, 2018. https://www.firstwordpharma.com/node/1542930.

68. Doody RS, Raman R, Farlow M, Iwatsubo T, Vellas B, Joffe S, Kieburtz K, He F, Sun X, Thomas RG, et al; Alzheimer's Disease Cooperative Study Steering Committee; Semagacestat Study Group: A phase 3 trial of semagacestat for treatment of Alzheimer's disease. N Engl J Med 369: 341-350, 2013.
69. Yang L, Hao J, Zhang J, Xia W, Dong X, Hu X, Kong F and Cui X: Ginsenoside $\operatorname{Rg} 3$ promotes beta-amyloid peptide degradation by enhancing gene expression of neprilysin. J Pharm Pharmacol 61 : 375-380, 2009

70. He Y, Zhao H and Su G: Ginsenoside Rg1 decreases neurofibrillary tangles accumulation in retina by regulating activities of neprilysin and PKA in retinal cells of AD mice model. J Mol Neurosci 52: 101-106, 2014

71. Tohda C, Matsumoto N, Zou K, Meselhy MR and Komatsu K: Abeta(25-35)-induced memory impairment, axonal atrophy, and synaptic loss are ameliorated by M1, A metabolite of protopanaxadiol-type saponins. Neuropsychopharmacology 29: $860-868,2004$

72. Androutsopoulos VP, Kanavouras K and Tsatsakis AM: Role of paraoxonase 1 (PON1) in organophosphate metabolism: Implications in neurodegenerative diseases. Toxicol Appl Pharmacol 256: 418-424, 2011

73. Li N, Liu Y, Li W, Zhou L, Li Q, Wang X and He P: A UPLC/MS-based metabolomics investigation of the protective effect of ginsenosides Rg1 and Rg2 in mice with Alzheimer's disease. J Ginseng Res 40: 9-17, 2016.

74. Li N, Zhou L, Li W, Liu Y, Wang J and He P: Protective effects of ginsenosides $\mathrm{Rg} 1$ and Rb1 on an Alzheimer's disease mouse model: A metabolomics study. J Chromatogr B Analyt Technol Biomed Life Sci 985: 54-61, 2015.

75. Li F, Wu X, Li J and Niu Q: Ginsenoside Rg1 ameliorates hippocampal long-term potentiation and memory in an Alzheimer's disease model. Mol Med Rep 13: 4904-4910, 2016.

76. Li X, Liu Y, Zhang X, Yuan H and Quan Q: [Effect of ginsenoside $\mathrm{Rg} 1$ on expressions of phosphory protein tau and N-methyl-D-aspartate receptor subunits NR1 and NR2B in rat brain slice model of Alzheimer's disease]. Zhongguo Zhong Yao Za Zhi 35: 3339-3343, 2010 (In Chinese).

77. Roberson ED, Halabisky B, Yoo JW, Yao J, Chin J, Yan F, Wu T, Hamto P, Devidze N, Yu GQ, et al: Amyloid- $\beta /$ Fyn-induced synaptic, network, and cognitive impairments depend on tau levels in multiple mouse models of Alzheimer's disease. J Neurosci 31 700-711, 2011

78. Broestl L, Worden K, Moreno AJ, Davis EJ, Wang D, Garay B, Singh T, Verret L, Palop JJ and Dubal DB: Ovarian Cycle Stages Modulate Alzheimer-Related Cognitive and Brain Network Alterations in Female Mice. eNeuro 5: pii: ENEURO.0132-17.2018, 2018.

79. Yang JT, Wang ZJ, Cai HY, Yuan L, Hu MM, Wu MN and Qi JS: Sex Differences in Neuropathology and Cognitive Behavior in APP/PS1/tau Triple-Transgenic Mouse Model of Alzheimer's Disease. Neurosci Bull 34: 736-746, 2018.

80. Wang Y, Kan H, Yin Y, Wu W, Hu W, Wang M, Li W and $\mathrm{Li}$ W: Protective effects of ginsenoside Rg1 on chronic restraint stress induced learning and memory impairments in male mice. Pharmacol Biochem Behav 120: 73-81, 2014.

81. Mu JS,Lin H, Ye JX,Lin Mand Cui XP: Rg1 exhibits neuroprotective effects by inhibiting the endoplasmic reticulum stress-mediated c-Jun N-terminal protein kinase apoptotic pathway in a rat model of Alzheimer's disease. Mol Med Rep 12: 3862-3868, 2015.

82. Wang ZJ, Sun L, Peng W, Ma S, Zhu C, Fu F and Heinbockel T: Ginseng derivative ocotillol enhances neuronal activity through increased glutamate release: A possible mechanism underlying increased spontaneous locomotor activity of mice. Neuroscience 195: 1-8, 2011.

83. Wang C-M, Liu M-Y, Wang F, Wei MJ, Wang S, Wu CF and Yang JY: Anti-amnesic effect of pseudoginsenoside-F11 in two mouse models of Alzheimer's disease. Pharmacol Biochem Behav 106: 57-67, 2013

84. Yan S, Li Z, Li H, Arancio O and Zhang W: Notoginsenoside R1 increases neuronal excitability and ameliorates synaptic and memory dysfunction following amyloid elevation. Sci Rep 4: 6352, 2014.

85. Wang Y, Liu J, Zhang Z, Bi P, Qi Z and Zhang C: Anti neuroinflammation effect of ginsenoside $\mathrm{Rbl}$ in a rat model of Alzheimer disease. Neurosci Let 487: 70-72, 2011.

86. Lv C, Li Q, Zhang Y, Sui Z, He B, Xu H, Yin Y, Chen X and Bi K: A UFLC-MS/MS method with a switching ionization mode for simultaneous quantitation of polygalaxanthone III, four ginsenosides and tumulosic acid in rat plasma: Application to a comparative pharmacokinetic study in normal and Alzheimer's disease rats. J Mass Spectrom 48: 904-913, 2013.

87. Liu J, Yan X, Li L, Zhu Y, Qin K, Zhou L, Sun D, Zhang X, Ye R and Zhao G: Ginsennoside rd attenuates cognitive dysfunction in a rat model of Alzheimer's disease. Neurochem Res 37: 2738-2747, 2012. 
88.Liu J, Yan X, Li L, Li Y, Zhou L, Zhang X, Hu X and Zhao G: Gingenoside Rd Improves Learning and Memory Ability in APP Transgenic Mice. J Mol Neurosci 57: 522-528, 2015.

89. Hwang SH, Shin EJ, Shin TJ, Lee BH, Choi SH, Kang J, Kim HJ, Kwon SH, Jang CG, Lee JH, et al: Gintonin, a ginseng-derived lysophosphatidic acid receptor ligand, attenuates Alzheimer's disease-related neuropathies: Involvement of non-amyloidogenic processing. J Alzheimers Dis 31: 207-223, 2012.

90. Choi DW and Rothman SM: The role of glutamate neurotoxicity in hypoxic-ischemic neuronal death. Annu Rev Neurosci 13: 171-182, 1990.

91. Braughler JM and Hall ED: Central nervous system trauma and stroke. I. Biochemical considerations for oxygen radical formation and lipid peroxidation. Free Radic Biol Med 6: 289-301, 1989.

92. Sousa SC, Maciel EN, Vercesi AE and Castilho RF: $\mathrm{Ca}^{2+}$-induced oxidative stress in brain mitochondria treated with the respiratory chain inhibitor rotenone. FEBS Lett 543: 179-183, 2003.

93. Dante S, Hauss T and Dencher NA: $\beta$-amyloid 25 to 35 is intercalated in anionic and zwitterionic lipid membranes to different extents. Biophys J 83: 2610-2616, 2002.

94.Ekinci FJ, Malik KU and Shea TB: Activation of the $\mathrm{L}$ voltage-sensitive calcium channel by mitogen-activated protein (MAP) kinase following exposure of neuronal cells to $\beta$-amyloid. MAP kinase mediates $\beta$-amyloid-induced neurodegeneration. J Biol Chem 274: 30322-30327, 1999.

95. CuiJ, Wang J,Zheng M, Gou D,Liu CandZhou Y: GinsenosideRg2 protects PC12 cells against $\beta$-amyloid25-35-induced apoptosis via the phosphoinositide 3-kinase/Akt pathway. Chem Biol Interact 275: 152-161, 2017.

96.Li N, Liu B, Dluzen DE and Jin Y: Protective effects of ginsenoside $\operatorname{Rg} 2$ against glutamate-induced neurotoxicity in PC12 cells. J Ethnopharmacol 111: 458-463, 2007.

97. Chen X, Huang T, Zhang J, Song J, Chen L and Zhu Y: Involvement of calpain and p25 of CDK5 pathway in ginsenoside Rb1's attenuation of $\beta$-amyloid peptide25-35-induced tau hyperphosphorylation in cortical neurons. Brain Res 1200: 99-106, 2008.

98. Quan QK, Li X, Yuan HF, Wang Y and Liu WL: Ginsenoside Rg1 inhibits high-voltage-activated calcium channel currents in hippocampal neurons of beta-amyloid peptide-exposed rat brain slices. Chin J Integr Med: Jan 15, 2016. (Epub ahead of print)

99.Kim S and Rhim H: Ginsenosides inhibit NMDA receptor-mediated epileptic discharges in cultured hippocampal neurons. Arch Pharm Res 27: 524-530, 2004.

100. Shin E-J, Koh YH, Kim A-Y, Nah SY, Jeong JH, Chae JS, Kim SC, Yen TP, Yoon HJ and Kim WK: Ginsenosides attenuate kainic acid-induced synaptosomal oxidative stress via stimulation of adenosine $\mathrm{A}(2 \mathrm{~A})$ receptors in rat hippocampus. Behav Brain Res 197: 239-245, 2009.

101. Blomgren K, Zhu C, Wang X, Karlsson JO, Leverin AL, Bahr BA, Mallard C and Hagberg H: Synergistic activation of caspase-3 by $\mathrm{m}$-calpain after neonatal hypoxia-ischemia-a mechanism of pathological apoptosis. J Biol Chem 276: 10191-10198, 2001

102. Gervais FG, Xu D, Robertson GS, Vaillancourt JP, Zhu Y, Huang J, LeBlanc A, Smith D, Rigby M, Shearman MS, et al: Involvement of caspases in proteolytic cleavage of Alzheimer's amyloid- $\beta$ precursor protein and amyloidogenic A $\beta$ peptide formation. Cell 97: 395-406, 1999.

103.Li H, Song J, Zhang J, Wang T, Yan Y, Tao Z, Li S, Zhang H, Kang $\mathrm{T}$ and Yang J: Ginseng protein reverses amyloid beta peptide and $\mathrm{H}_{2} \mathrm{O}_{2}$ cytotoxicity in neurons, and ameliorates cognitive impairment in $\mathrm{AD}$ rats induced by a combination of D-galactose and AlCl3. Phytother Res 31: 284-295, 2017.

104. Choi RCY, Zhu JT, Leung KW, Chu GK, Xie HQ, Chen VP, Zheng KY, Lau DT, Dong TT, Chow PC, et al: A flavonol glycoside, isolated from roots of Panax notoginseng, reduces amyloid- $\beta$-induced neurotoxicity in cultured neurons: Signaling transduction and drug development for Alzheimer's disease. J Alzheimers Dis 19: 795-811, 2010.

105. May MJ and Ghosh S: IkappaB kinases: Kinsmen with different crafts. Science 284: 271-273, 1999.

106. Boissière F, Hunot S, Faucheux B, Duyckaerts C, Hauw JJ, Agid Y and Hirsch EC: Nuclear translocation of NF-kappaB in cholinergic neurons of patients with Alzheimer's disease. Neuroreport 8: 2849-2852, 1997.

107. Park EK, Shin YW, Lee HU, Kim SS, Lee YC, Lee BY and $\mathrm{Kim}$ DH: Inhibitory effect of ginsenoside Rb1 and compound $\mathrm{K}$ on $\mathrm{NO}$ and prostaglandin E2 biosyntheses of RAW264.7 cells induced by lipopolysaccharide. Biol Pharm Bull 28: 652-656, 2005.
108. Kim SF, Huri DA and Snyder SH: Inducible nitric oxide synthase binds, S-nitrosylates, and activates cyclooxygenase-2. Science 310: 1966-1970, 2005.

109. Prast $\mathrm{H}$ and Philippu A: Nitric oxide as modulator of neuronal function. Prog Neurobiol 64: 51-68, 2001.

110. Li Y, Zhao Y, Li G, Wang J, Li T, Li W and Lu J: Regulation of neuronal nitric oxide synthase exon if gene expression by nuclear factor-kappaB acetylation in human neuroblastoma cells. J Neurochem 101: 1194-1204, 2007.

111. Kashour T, Burton T, Dibrov A and Amara FM: Late Simian virus 40 transcription factor is a target of the phosphoinositide 3-kinase/Akt pathway in anti-apoptotic Alzheimer's amyloid precursor protein signalling. Biochem J 370: 1063-1075, 2003.

112. van der Heide LP, Ramakers GMJ and Smidt MP: Insulin signaling in the central nervous system: Learning to survive. Prog Neurobiol 79: 205-221, 2006.

113. Nunomura A, Perry G, Aliev G, Hirai K, Takeda A, Balraj EK, Jones PK, Ghanbari H, Wataya T, Shimohama S, et al: Oxidative damage is the earliest event in Alzheimer disease. J Neuropathol Exp Neurol 60: 759-767, 2001.

114. Li H, Kang T, Qi B, Kong L, Jiao Y, Cao Y, Zhang J and Yang J: Neuroprotective effects of ginseng protein on PI3K/Akt signaling pathway in the hippocampus of $\mathrm{D}$-galactose/ $\mathrm{AlCl} 3$ inducing rats model of Alzheimer's disease. J Ethnopharmacol 179: 162-169, 2016.

115. Kanemaru K: Immunotherapy targeting misfolded proteins in neurodegenerative disease. Brain Nerv 65: 469-474, 2013 (In Japanese).

116. Song XY, Hu JF, Chu SF, Zhang Z, Xu S, Yuan YH, Han N, Liu Y, Niu F, He X and Chen NH: Ginsenoside Rg1 attenuates okadaic acid induced spatial memory impairment by the GSK $3 \beta /$ tau signaling pathway and the $A \beta$ formation prevention in rats. Eur J Pharmacol 710: 29-38, 2013.

117. PlattnerF, Angelo M and Giese KP: The roles of cyclin-dependent kinase 5 and glycogen synthase kinase 3 in tau hyperphosphorylation. J Biol Chem 281: 25457-25465, 2006.

118. Li L, Liu Z, Liu J, Tai X, Hu X, Liu X, Wu Z, Zhang G, Shi M and Zhao G: Ginsenoside Rd attenuates beta-amyloid-induced tau phosphorylation by altering the functional balance of glycogen synthase kinase 3 beta and protein phosphatase 2A. Neurobiol Dis 54: 320-328, 2013.

119. Zhang X, Shi M, Ye R, Wang W, Liu X, Zhang G, Han J, Zhang Y, Wang B, Zhao J, et al: Ginsenoside Rd attenuates tau protein phosphorylation via the PI3K/AKT/GSK-3 $\beta$ pathway after transient forebrain ischemia. Neurochem Res 39: 1363-1373, 2014.

120. Liu F, Shi J, Tanimukai H, Gu J, Gu J, Grundke-Iqbal I, Iqbal K and Gong CX: Reduced O-GlcNAcylation links lower brain glucose metabolism and tau pathology in Alzheimer's disease. Brain 132: 1820-1832, 2009.

121.Li L, Liu J, Yan X, Qin K, Shi M, Lin T, Zhu Y, Kang T and Zhao G: Protective effects of ginsenoside Rd against okadaic acid-induced neurotoxicity in vivo and in vitro. J Ethnopharmacol 138: 135-141, 2011.

122. Xu B, Gottschalk W, Chow A, Wilson RI, Schnell E, Zang K, Wang D, Nicoll RA, Lu B and Reichardt LF: The role of brain-derived neurotrophic factor receptors in the mature hippocampus: Modulation of long-term potentiation through a presynaptic mechanism involving TrkB. J Neurosci 20: 6888-6897, 2000

123. Sakata K, Mastin JR, Duke SM, Vail MG, Overacre AE, Dong BE and Jha S: Effects of antidepressant treatment on mice lacking brain-derived neurotrophic factor expression through promoter IV. Eur J Neurosci 37: 1863-1874, 2013.

124. West AE, Chen WG, Dalva MB, Dolmetsch RE, Kornhauser JM, Shaywitz AJ, Takasu MA, Tao X and Greenberg ME: Calcium regulation of neuronal gene expression. Proc Natl Acad Sci USA 98: 11024-11031, 2001.

125. Shi YQ, Huang TW, Chen LM, Pan XD, Zhang J, Zhu YG and Chen XC: Ginsenoside Rg1 attenuates amyloid- $\beta$ content, regulates $\mathrm{PKA} / \mathrm{CREB}$ activity, and improves cognitive performance in SAMP8 mice. J Alzheimers Dis 19: 977-989, 2010.

126. Bao C, Wang Y, Min H, Zhang M, Du X, Han R and Liu X: Combination of ginsenoside $\mathrm{Rg} 1$ and bone marrow mesenchymal stem cell transplantation in the treatment of cerebral ischemia reperfusion injury in rats. Cell Physiol Biochem 37: 901-910, 2015. 
127.Zhou Y, Li HQ, Lu L, Fu DL, Liu AJ, Li JH and Zheng GQ Ginsenoside Rg1 provides neuroprotection against blood brain barrier disruption and neurological injury in a rat model of cerebral ischemia/reperfusion through downregulation of aquaporin 4 expression. Phytomedicine 21: 998-1003, 2014.

128. Li Y, Guan Y, Wang Y, Yu CL, Zhai FG and Guan LX Neuroprotective effect of the ginsenoside $\mathrm{Rg} 1$ on cerebral ischemic injury in vivo and in vitro is mediated by PPAR $\gamma$ regulated antioxidative and anti-inflammatory pathways. Evid Based Complement Alternat Med 2017: 7842082, 2017. doi: 10.1155/2017/7842082.

129. Yang Y, Li X, Zhang L, Liu L, Jing G and Cai H: Ginsenoside Rg1 suppressed inflammation and neuron apoptosis by activating PPAR $\gamma / \mathrm{HO}-1$ in hippocampus in rat model of cerebral ischemia-reperfusion injury. Int J Clin Exp Pathol 8: 2484-2494, 2015

130.Lin M, Sun W, Gong W, Ding Y, Zhuang Y and Hou Q: Ginsenoside Rg1 protects against transient focal cerebra ischemic injury and suppresses its systemic metabolic changes in cerebral injury rats. Acta Pharmaceutica Sinica B 5: 277-284, 2015

131. XieCL,LiJH,Wang WW,Zheng GQ andWang LX:Neuroprotective effect of ginsenoside-Rg1 on cerebral ischemia/reperfusion injury in rats by downregulating protease-activated receptor-1 expression. Life Sci 121: 145-151, 2015

132. Sun C, Lai X, Huang X and Zeng Y: Protective effects of ginsenoside $\mathrm{Rg} 1$ on astrocy tes and cerebral ischemic-reperfusion mice. Biol Pharm Bull 37: 1891-1898, 2014.

133.Li J, Liu Y, Li W, Wang Z, Guo P, Li L and Li N: Metabolic profiling of the effects of ginsenoside Re in an Alzheimer's disease mouse model. Behav Brain Res 337: 160-172, 2018.

134. Hwang JY, Shim JS, Song MY, Yim SV, Lee SE and Park KS Proteomic analysis reveals that the protective effects of ginsenoside $\mathrm{Rb} 1$ are associated with the actin cytoskeleton in $\beta$-amyloid-treated neuronal cells. J Ginseng Res 40: 278-284, 2016.

135. Dubois B, Feldman HH, Jacova C, Dekosky ST, BarbergerGateau P, Cummings J, Delacourte A, Galasko D, Gauthier S, Jicha G, et al: Research criteria for the diagnosis of Alzheimer's disease: revising the NINCDS-ADRDA criteria. Lancet Neurol 6 : 734-746, 2007

136. Heo JH, Lee ST, Chu K, Oh MJ, Park HJ, Shim JY and Kim M: Heat-processed ginseng enhances the cognitive function in patients with moderately severe Alzheimer's disease. Nutr Neurosci 15: 278-282, 2012.

137. Yang Q, Lin J, Zhang H, Liu Y, Kan M, Xiu Z, Chen X, Lan X, Shi $X, \mathrm{Li} N$ and $\mathrm{Qu} X$ : Ginsenoside compound $\mathrm{K}$ regulates amyloid $\beta$ via the Nrf2/Keap1 signalling pathway in mice with scopolamine hydrobromide-induced memory impairments. J Mol Neurosci 67: 62-71, 2019.

138. Lee ST, Chu K, Sim JY, Heo JH and Kim M: Panax ginseng enhances cognitive performance in Alzheimer disease. Alzheimer Dis Assoc Disord 22: 222-226, 2008.

139. Heo JH, Lee ST, Chu K, Oh MJ, Park HJ, Shim JY and Kim M: An open-label trial of Korean red ginseng as an adjuvant treatment for cognitive impairment in patients with Alzheimer's disease. Eur J Neurol 15: 865-868, 2008.

140. Heo JH, Park MH and Lee JH: Effect of Korean red ginseng on cognitive function and quantitative EEG in patients with Alzheimer's disease: A preliminary study. J Altern Complement Med 22: 280-285, 2016.

141. Heo JH, Lee ST, Oh MJ, Park HJ, Shim JY, Chu K and Kim M: Improvement of cognitive deficit in Alzheimer's disease patients by long term treatment with korean red ginseng. J Ginseng Res 35: 457-461, 2011.

142. Burns A, Gauthier S and Perdomo C: Efficacy and safety of donepezil over 3 years: An open-label, multicentre study in patients with Alzheimer's disease. Int J Geriatr Psychiatry 22: 806-812, 2007.

143. Minthon L, Wallin AK, Eriksson S, Wattmo C and Andreasen N: Long-term rivastigmine treatment in a routine clinical setting. Acta Neurol Scand 119: 180-185, 2009.

144. Scholey A, Ossoukhova A, Owen L, Ibarra A, Pipingas A, $\mathrm{He}$ K, Roller M and Stough C: Effects of American ginseng (Panax quinquefolius) on neurocognitive function: An acute, randomised, double-blind, placebo-controlled, crossover study. Psychopharmacology (Berl) 212: 345-356, 2010.

145.Liu L, Hoang-Gia T, Wu H, Lee MR, Gu L, Wang C, Yun BS Wang Q, Ye S and Sung CK: Ginsenoside Rb1 improves spatial learning and memory by regulation of cell genesis in the hippocampal subregions of rats. Brain Res 1382: 147-154, 2011.
146. Huang T, Fang F, Chen L, Zhu Y, Zhang J, Chen X and Yan SS: Ginsenoside Rg1 attenuates oligomeric A 31 -42-induced mitochondrial dysfunction. Curr Alzheimer Res 9: 388-395, 2012.

147.Zhang JT, Liu Y, Qu ZW, Zhang XL and Xiao HL: [Influence of ginsenoside $\mathrm{Rbl}$ and $\mathrm{Rg} 1$ on some central neurotransmitter receptors and protein biosynthesis in the mouse brain]. Yao Xue Xue Bao 23: 12-16, 1988 (In Chinese).

148. Ying Y, Zhang JT, Shi CZ, Qu ZW and Liu Y: [Study on the nootropic mechanism of ginsenoside Rb1 and Rg1--influence on mouse brain development]. Acta pharmaceutica Sinica 29: 241-245, 1994 (In Chinese).

149.Zeng XS, Zhou XS, Luo FC, Jia JJ, Qi L, Yang ZX, Zhang W and Bai J: Comparative analysis of the neuroprotective effects of ginsenosides Rg1 and Rb1 extracted from Panax notoginseng against cerebral ischemia. Can J Physiol Pharmacol 92: 102-108, 2014.

150. Huang XP, Ding H, Lu JD, Tang YH, Deng BX and Deng CQ: Effects of the combination of the main active components of Astragalus and Panax notoginseng on inflammation and apoptosis of nerve cell after cerebral ischemia-reperfusion. Am J Chin Med 43: 1419-1438, 2015

151. Wang X, Zeng C, Lin J, Chen T, Zhao T, Jia Z, Xie X, Qiu Y, Su M, Jiang T, et al: Metabonomics approach to assessing the modulatory effects of St John's wort, ginsenosides, and clomipramine in experimental depression. J Proteome Res 11: 6223-6230, 2012

152. Yamada N, Araki $\mathrm{H}$ and Yoshimura $\mathrm{H}$ : Identification of antidepressant-like ingredients in ginseng root (Panax ginseng C.A.Meyer) using a menopausal depressive-like state in female mice: Participation of 5- $\mathrm{HT}_{2 \mathrm{~A}}$ receptors. Psychopharmacology (Berl) 216: 589-599, 2011.

153. Kang A, Hao H, Zheng X, Liang Y, Xie Y, Xie T, Dai C, Zhao Q, Wu X, Xie L and Wang G: Peripheral anti-inflammatory effects explain the ginsenosides paradox between poor brain distribution and anti-depression efficacy. J Neuroinflammation 8: $100,2011$.

154.Zhang H, Li Z, Zhou Z, Yang H, Zhong Z and Lou C: Antidepressant-like effects of ginsenosides: A comparison of ginsenoside $\mathrm{Rb} 3$ and its four deglycosylated derivatives, $\mathrm{Rg}_{3}$, $\mathrm{Rh}_{2}$, compound $\mathrm{K}$, and $20(S)$-protopanaxadiol in mice models of despair. Pharmacol Biochem Behav 140: 17-26, 2016.

155. You Z, Yao Q, Shen J, Gu Z, Xu H, Wu Z, Chen C and Li L: Antidepressant-like effects of ginsenoside Rg3 in mice via activation of the hippocampal BDNF signaling cascade. J Nat Med 71: 367-379, 2017

156. Liu X-Y, Zhou X-Y, Hou J-C, Zhu H, Wang Z, Liu JX and Zheng YQ: Ginsenoside Rd promotes neurogenesis in rat brain after transient focal cerebral ischemia via activation of PI3K/Akt pathway. Acta Pharmacol Sin 36: 421-428, 2015.

157. Xie Z, Shi M, Zhang C, Zhao H, Hui H and Zhao G: Ginsenoside $\mathrm{Rd}$ protects against cerebral ischemia-reperfusion injury via decreasing the expression of the NMDA receptor $2 \mathrm{~B}$ subunit and its phosphorylated product. Neurochem Res 41: 2149-2159, 2016.

158. Chen LM, Zhou XM, Cao YL and Hu WX: Neuroprotection of ginsenoside Re in cerebral ischemia-reperfusion injury in rats. J Asian Nat Prod Res 10: 439-445, 2008.

159. He B, Chen P, Yang J, Yun Y, Zhang X, Yang R and Shen Z: Neuroprotective effect of $20(\mathrm{R})$-ginsenoside $\operatorname{Rg}(3)$ against transient focal cerebral ischemia in rats. Neurosci Lett 526 $106-111,2012$

160. Jiang B, Xiong Z, Yang J, Wang W, Wang Y, Hu ZL, Wang F and Chen JG: Antidepressant-like effects of ginsenoside Rg1 are due to activation of the BDNF signalling pathway and neurogenesis in the hippocampus. Br J Pharmacol 166: 1872-1887, 2012.

161. Liu Z, Qi Y, Cheng Z, Zhu X, Fan C and Yu SY: The effects of ginsenoside $\mathrm{Rg} 1$ on chronic stress induced depression-like behaviors, BDNF expression and the phosphorylation of PKA and CREB in rats. Neuroscience 322: 358-369, 2016.

162. Cui J, Jiang L and Xiang H: Ginsenoside Rb3 exerts antidepressant-like effects in several animal models. J Psychopharmacol 26: 697-713, 2012.

This work is licensed under a Creative Commons Attribution-NonCommercial-NoDerivatives 4.0 International (CC BY-NC-ND 4.0) License. 